Verena Pfeifer, Travis E. Jones, Juan J. Velasco Vélez, Cyriac Massué, Rosa Arrigo, Detre Teschner, Frank Girgsdies, Michael Scherzer, Mark T. Greiner, Jasmin Allan, Maike Hashagen, Gisela Weinberg, Simone Piccinin, Michael Hävecker, Axel Knop-Gericke, Robert Schlögl

\title{
The electronic structure of iridium and its oxides
}

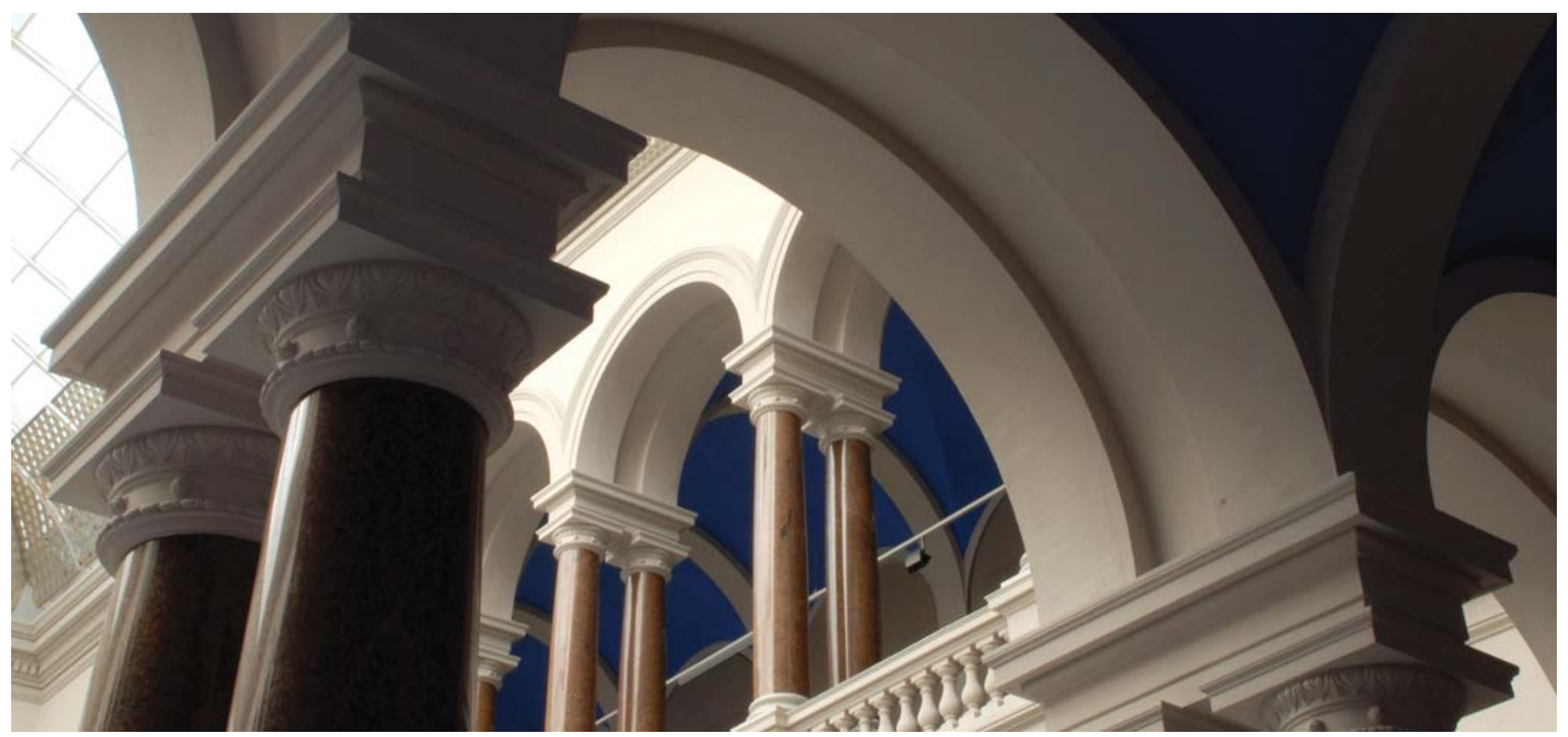

This is the peer reviewed version of the following article:

Pfeifer, V., Jones, T. E., Velasco Vélez, J. J., Massué, C., Arrigo, R., Teschner, D., Scherzer, M., Greiner, M. T., Allan, J. Girgsdies, F., Hashagen, M., Weinberg, G., Piccinin, S., Hävecker, M., Knop-Gericke, A., Schlögl, R. (2015). The electronic structure of iridium and its oxides. Surface and Interface Analysis, 48 (5), 261-273. https://doi.org/10.1002/sia.5895

which has been published in final form at https://doi.org/10.1002/sia.5895. This article may be used for non-commercial purposes in accordance with Wiley Terms and Conditions for Use of Self-Archived Versions. 


\section{The electronic structure of iridium and its oxides $\$$}

Verena Pfeifer, Travis E. Jones, Juan J. Velasco Vélez, Cyriac Massué, Rosa Arrigo, Detre Teschner, Frank Girgsdies, Michael Scherzer, Mark T. Greiner, Jasmin Allan, Maike Hashagen, Gisela Weinberg, Simone Piccinin, Michael Hävecker, Axel Knop-Gericke, \& Robert Schlögl

\section{Abstract}

Iridium-based materials are among the most active and stable electrocatalysts for the oxygen evolution reaction. Amorphous iridium oxide structures are found to be more active than their crystalline counterparts. Herein, we combine synchrotron-based Xray photoemission and absorption spectroscopies with theoretical calculations to investigate the electronic structure of Ir metal, rutile-type $\mathrm{IrO}_{2}$, and an amorphous $\mathrm{IrO}_{\mathbf{x}}$. Theory and experiment show that while the Ir $4 \mathrm{f}$ line shape of Ir metal is well described by a simple Doniach-Šunjić function, the peculiar line shape of rutile-type $\mathrm{IrO}_{2}$ requires the addition of a shake-up satellite $1 \mathrm{eV}$ above the main line. In the catalytically more active amorphous $\mathrm{IrO}_{x}$, we find that additional intensity appears in the $\mathrm{Ir} 4 \mathrm{f}$ spectrum at higher binding energy when compared with rutile-type $\mathrm{IrO}_{2}$ along with a pre-edge feature in the $\mathrm{OK}$-edge. We identify these additional features as electronic defects in the anionic and cationic frameworks, namely formally $\mathrm{O}^{\mathrm{I}-}$ and $\mathrm{Ir}^{\mathrm{III}}$, which may explain the increased activity of amorphous $\mathrm{IrO}_{x}$ electrocatalysts. We corroborate our findings by in situ X-ray diffraction as well as in situ X-ray photoemission and absorption spectroscopies.

\footnotetext{
$\S$ This is the peer reviewed version of the following article: "Pfeifer, V., Jones, T. E., Velasco Vélez, J. J., Massué, C., Arrigo, R., Teschner, D., Girgsdies, F., Scherzer, M., Greiner, M. T., Allan, J., Hashagen, M., Weinberg, G., Piccinin, S., Hävecker, M., Knop-Gericke, A., and Schlögl, R. 2016 The electronic structure of iridium and its oxides. Surf. Interface Anal., 48, 258-270, doi: 10.1002/sia.5895."

This article may be used for non-commercial purposes in accordance with Wiley Terms and Conditions for Self-Archiving.

This peer reviewed version is available at http://doi.org/10.14279/depositonce-5873, page numbers differ.
} 


\section{Introduction}

A major challenge facing efforts to transition to a clean and renewable energy supply is finding feasible means of storing excess energy from intermittent resources. Water electrolysis, which converts electrical into chemical energy by the generation of hydrogen and oxygen from water, is a key technology in this field. ${ }^{1}$ The hydrogen generated by this method can either be fed into fuel cells or used in the synthesis of chemical feedstocks. However, to date, a sustainable, economic, and stable system for mass production of hydrogen by water electrolysis is lacking. A factor hampering the successful development of such a system is the sluggish oxygen evolution reaction (OER), which requires the transfer of four electrons and four protons. The proton transfer between the electrodes is typically achieved via proton exchange membranes. While this membrane technology is mature, taking advantage of it involves the development of OER electrocatalysts that are both active and stable under the required acidic working conditions. Conducting iridium oxide is the electrocatalyst that represents the best compromise between high activity and stability in acidic environments. ${ }^{2,3}$

The high activity of iridium oxides for catalyzing the OER, when compared with other materials, has been discussed for decades. ${ }^{4,5}$ Such studies have revealed that upon electrochemical cycling of bulk Ir metal within a specific potential window, a hydrated, amorphous iridium oxide surface layer forms with an accompanying increase in OER activity. ${ }^{6,7}$ The scarcity of iridium has led researchers to refrain from studies on bulk iridium materials and focus on high surface area iridium oxide structures with the aim of optimizing iridium usage. ${ }^{8}$ From these attempts, it was found that amorphous iridium oxide catalysts exhibit higher OER activities than crystalline ones. ${ }^{9,10}$ These findings have prompted studies aimed at identifying and understanding the nature of the active species in iridium oxide catalysts.

Researchers have tried to correlate the electronic structure of iridium oxide with its OER activity by means of X-ray photoemission spectroscopy (XPS) in an effort to identify active surface species. ${ }^{6,11-14}$ Unambiguous speciation, however, has proven elusive because the combined influence of band structure, electron correlation, and spin-orbit coupling on the electronic structure of iridium oxide has not yet been resolved. ${ }^{15}$ For example, as a conductor, the core level spectra of rutile-type $\mathrm{IrO}_{2}$ are expected to be asymmetric, as described by the Doniach-Šunjić (DS) line shape. However, the Ir $4 \mathrm{f}$ spectrum of crystalline rutile-type $\mathrm{IrO}_{2}$ cannot be fit with the conventional DS line profile. The origin of this peculiar line shape has been debated in literature. ${ }^{16-18}$

In this study, we investigate two reference iridium oxides, one crystalline and one amorphous, and correlate their electrocatalytic activities with their electronic structures. To develop a well-defined reference, we first combine XPS with theoretical calcu- 
lations to explain the origin of the unusual line shape of rutile-type $\mathrm{IrO}_{2}$. Subsequently, we complement XPS with the near-edge X-ray absorption fine structure (NEXAFS) of the OK-edge and identify additional species present in the catalytically more active amorphous $\mathrm{IrO}_{x}$ powder. Finally, we test the robustness of our proposed models by in situ X-ray diffraction (XRD) and in situ XPS/NEXAFS investigations.

\section{Experimental}

\section{Powder sample characterization methods}

Prior to the X-ray photoemission and absorption experiments, two commercially available iridium oxide powders from Sigma-Aldrich (99.9\% trace metals basis) and AlfaAesar (Premion ${ }^{\circledR}, 99.99 \%$, trace metals basis) were thoroughly characterized.

First, XRD was used to investigate the powders in the as-received state and after calcination at $1073 \mathrm{~K}$ for $50 \mathrm{~h}$ in $10^{5} \mathrm{~Pa} \mathrm{O}_{2}$. XRD was measured in Bragg-Brentano geometry on a Bruker AXS D8 Advance $\theta / \theta$ diffractometer using Ni-filtered $\mathrm{Cu} \mathrm{K} \alpha$ radiation and a position-sensitive LynxEye silicon strip detector. The powders were filled into the recess of a cup-shaped sample holder, the surface of the powder bed being flush with the sample holder edge (front loading). Second, the as-received powder morphologies were observed, and their atomic compositions were determined in a scanning electron microscope (SEM) Hitachi S-4800 FEG equipped with a Bruker XFlash detector and an energy dispersive X-ray spectroscopy (EDX) system Quantax. The images were taken with an acceleration voltage of $1.5 \mathrm{kV}$ in SE mode, and the atomic compositions were determined via EDX at $25 \mathrm{kV}$. After degassing the samples for $3 \mathrm{~h}$ at $353 \mathrm{~K}$, the surface area of the powders was measured in $\mathrm{N}_{2}$ at $77 \mathrm{~K}$ by the Brunauer-Emmett-Teller (BET) method using an Autosorb 6-MP from Quantachrome.

Thermal analysis of the samples was carried out via thermogravimetry (TG) and differential scanning calorimetry (DSC) using a Netzsch STA449C Jupiter instrument. The samples were heated to $1073 \mathrm{~K}$ at a constant heating rate of $10 \mathrm{~K} \mathrm{~min}^{-1}$ in $21 \mathrm{vol} . \%$ $\mathrm{O}_{2}$ in $\mathrm{Ar}\left(100 \mathrm{~mL} \mathrm{~min}^{-1}\right)$ at $10^{5} \mathrm{~Pa}$. The resultant gaseous products were analyzed by a Pfeiffer QMS200 OmniStar quadrupole mass spectrometer. The overall iridium oxidation state of the powders was calculated based on a temperature-programmed reduction (TPR). The TPR profile was measured in a home-built plug-flow fixed-bed reactor in $4.92 \mathrm{vol} . \% \mathrm{H}_{2}$ in $\mathrm{Ar}\left(80 \mathrm{~mL} \mathrm{~min}^{-1}\right)$ at a heating rate of $6 \mathrm{~K} \mathrm{~min}^{-1}$ (end temperature $723 \mathrm{~K}$ ). The $\mathrm{H}_{2}$ consumption of $9.8 \mathrm{mg}$ rutile-type $\mathrm{IrO}_{2}$ and $8.3 \mathrm{mg}$ amorphous $\mathrm{IrO}_{x}$ was measured by a thermal conductivity detector. The detector was calibrated by reducing $34.5 \mathrm{mg}$ of $\mathrm{CuO}(\approx 99 \%$, trace metals basis) prior to the measurements. In the oxida- 
tion state determination, we assume a standard deviation of $2 \%$ based on repeated measurements of the reduction of a defined amount of $\mathrm{CuO} .{ }^{19}$

Finally, the OER performance of the powders was evaluated. For this, catalyst inks were prepared from ground iridium oxide powder, $60 \%$ water, 39.6\% isopropanol, and $0.4 \%$ Nafion (5\% perfluorinated resin solution, Sigma-Aldrich). Defined ink volumes were deposited on glassy carbon ring disk electrodes (Pine Instruments) with a micropipette and dried in air at $333 \mathrm{~K}$ for $30 \mathrm{~min}$ to achieve a constant loading of $20 \mu \mathrm{g}_{\mathrm{Ir}} \mathrm{cm}^{-2}$. Electrochemical measurements were performed at a rotational frequency of $1600 \mathrm{rpm}$ in $\mathrm{N}_{2}$-saturated $0.5 \mathrm{M} \mathrm{H}_{2} \mathrm{SO}_{4}$. For the linear sweep voltammetry (LSV), the potential was increased at a rate of $5 \mathrm{mV} \mathrm{s}^{-1}$ up to $1.8 \mathrm{~V}$ versus the standard hydrogen electrode (SHE).

\section{NAP-XPS and NEXAFS}

X-ray photoemission and absorption measurements were performed in a nearambient-pressure X-ray photoemission spectroscopy (NAP-XPS) system at the Innovative station for in situ spectroscopy beam line at the synchrotron facility BESSY II/HZB (Berlin, Germany). The setup is described in detail elsewhere. ${ }^{20}$ Monochromatic light was used to investigate the electronic structure of an Ir (111) single crystal (MaTecK, $99.99 \%$ trace metals basis) and the two iridium oxide powders, which were pressed into pellets of $8 \mathrm{~mm}$ diameter ( $40 \mathrm{mg}$ powder, $3 \mathrm{t}$ pressing weight). The samples were mounted onto a stainless steel backplate on a sapphire sample holder and fixed by a tantalum wire construction (single crystal) or a stainless steel lid with a $3 \mathrm{~mm}$ hole (powder pellets). The sample could be heated via the backplate by an infrared laser. The laser power was adjusted with a proportional integral derivative feedback loop controlled by a K-type thermocouple, which was in contact with the sample surface. The experiments were either performed in $\mathrm{UHV}\left(\approx 10^{-6} \mathrm{~Pa}\right)$ or in $25 \mathrm{~Pa} \mathrm{O}_{2}$. The gas flow was controlled by Bronkhorst mass flow controllers, and a constant pressure was ensured by a pressure-regulating valve. The exit slit setting of the beam line was $111 \mu \mathrm{m}$ for all measurements.

In XPS, a pass energy of $10 \mathrm{eV}$ was chosen, which, for the Ir $4 \mathrm{f}$ core line, yielded an approximate resolution of $0.2 \mathrm{eV}$ at $130 \mathrm{eV}$ kinetic energy (KE) of the photoelectrons, $0.3 \mathrm{eV}$ at $450 \mathrm{eV} \mathrm{KE}$, and $0.6 \mathrm{eV}$ at $900 \mathrm{eV} \mathrm{KE}$. The associated inelastic mean free paths of the photoelectrons are $\approx 0.4 \mathrm{~nm}, \approx 0.7 \mathrm{~nm}$, and $1.1 \mathrm{~nm}$, according to the model of Tanuma et al. ${ }^{21}$ The binding energy was calibrated by measuring the corresponding Fermi edge after each core level measurement.

In NEXAFS, the photon energy was varied from $525 \mathrm{eV}$ to $555 \mathrm{eV}$ by a continuous movement of the monochromator. The Auger electron yield at the OK-edge was mea- 
sured with the electron spectrometer to partly suppress the contribution of gas-phase $\mathrm{O}_{2}{ }^{22}$ by setting the $\mathrm{KE}$ to $385 \mathrm{eV}$ (pass energy $50 \mathrm{eV}$ ). The energy resolution was approximately $0.8 \mathrm{eV}$.

Prior to the room temperature measurements in UHV, the three types of sample were subjected to different pretreatments. The Ir single crystal was cleaned by cycles of $\mathrm{Ar}^{+}-$ sputtering $\left(2 \times 10^{2} \mathrm{~Pa}, 1.5 \mathrm{kV}, 20 \mathrm{~mA}, 15 \mathrm{~min}\right)$ and subsequent annealing $(873 \mathrm{~K}, 25 \mathrm{~Pa}$ $\mathrm{O}_{2}, 30 \mathrm{~min}$ ) before a final flashing in UHV to $873 \mathrm{~K}$. The powder from Sigma-Aldrich was washed in Milli-Q water to reduce the amount of impurities and then calcined at $1073 \mathrm{~K}$ in $10^{5} \mathrm{~Pa} \mathrm{O}_{2}$ for $50 \mathrm{~h}$ to achieve phase purity. The AlfaAesar $\mathrm{IrO}_{\mathrm{x}}$ was measured as received.

Following UHV measurements, the XPS and NEXAFS of the AlfaAesar $\mathrm{IrO}_{\mathrm{x}}$ were measured in situ. These experiments were performed by heating the sample in $25 \mathrm{~Pa}$ $\mathrm{O}_{2}$ to $523 \mathrm{~K}$ at $5 \mathrm{~K} \mathrm{~min}^{-1}$. Spectra were collected under these conditions. Afterwards, the temperature was increased to $673 \mathrm{~K}$, and spectra were recorded at a constant temperature.

The fitting of all core level spectra was performed after subtraction of a Shirley background with the commercially available CasaXPS software (www.casaxps.com). In all fits, the peak separation and the peak area ratios between the $\operatorname{Ir} 4 f_{7 / 2}$ and the $\operatorname{Ir} 4 f_{5 / 2}$ components were constrained to $3 \mathrm{eV}$ and $4: 3$, respectively. Deviations in the peak area ratios of $5 \%$ were allowed to account for the inevitable inaccuracies evoked by background subtraction and peak area determination of asymmetric peaks. Details on the fit functions can be found in Fairley and Carrick. ${ }^{23}$ In brief, DS $(\alpha, n)$ is a DS profile with the asymmetry parameter $\alpha$ that is convoluted with a Gaussian whose width is characterized by an integer $0 \leq n \leq 499$. The SGL $(m)$ function blends the DS function with a Gaussian-Lorentzian sum form on the low binding energy side of the peak maximum. The ratio of the sum form is given by the parameter $m$ (0 pure Gaussian and 100 pure Lorentzian). The SGL $(m)$ allows the spectra to be less Lorentzian in nature than the DS function would predict.

\section{In situ X-ray diffraction}

In situ XRD data were collected on a STOE $\theta / \theta$ X-ray diffractometer ( $\mathrm{Cu} \mathrm{K} \alpha_{1+2}$ radiation, secondary graphite monochromator and scintillation counter) equipped with an Anton Paar XRK 900 in situ reactor chamber. The gas feed was mixed with Bronkhorst mass flow controllers using $21 \mathrm{vol} . \% \mathrm{O}_{2}$ in helium at a total flow rate of $100 \mathrm{~mL} \mathrm{~min}^{-1}$. The effluent gas composition was monitored with a Pfeiffer OmniStar quadrupole mass spectrometer. Before the thermal treatment, the sample was characterized at $298 \mathrm{~K}$ with slow $\mathrm{XRD}$ scans $\left(15^{\circ}-75^{\circ} 2 \theta\right.$ with $0.02^{\circ}$ steps, 10 s per step counting time). 
During the temperature program, faster scans (1 s per step counting time and $70 \mathrm{~min}$ per scan) were performed. The sample was heated to $473 \mathrm{~K}$ at $20 \mathrm{~K} \mathrm{~min}^{-1}$ and then isothermal XRD scans were recorded every $50 \mathrm{~K}$ between $473 \mathrm{~K}$ and $873 \mathrm{~K}$ with intermediate heating ramps of $20 \mathrm{~K} \mathrm{~min}^{-1}$.

\section{Theoretical background and methods}

A major challenge with interpretation of XPS data on iridium oxides stems from their peculiar Ir $4 \mathrm{f}$ peak shape, which makes speciation ambiguous. As conductors, electron screening will make the X-ray lines in Ir metal and $\mathrm{IrO}_{2}$ asymmetric. If, for simplicity, we ignore lifetime, phonon, and instrumental broadening and assume constant excitation matrix elements, the asymmetric line shape is given by

$$
I(\omega)=\int_{-\infty}^{\infty} d t e^{-i \omega t} \exp \left[\int_{0}^{\infty} d \epsilon \frac{N_{\mathrm{eh}}}{\epsilon^{2}}\left(e^{-i \epsilon t}-1\right)\right],
$$

where $\omega$ is the energy, $t$ is the time, $N_{\text {eh }}$ is the electron hole pair excitation spectrum, and $\epsilon$ is the excitation energy (see reference 24 and references therein). It is well-known that there is no closed-form solution for this line shape. As such, the asymptotic solution is often employed, which can be found by assuming the density of states (DOS) does not vary, resulting in $N_{\text {eh }}=\alpha \epsilon$, where $\alpha$ is a constant. This solution, with the appropriate broadening, gives rise to the DS line shape. ${ }^{25}$ Formally, it holds only in the neighborhood of the Fermi energy $\left(E_{\mathrm{F}}\right)$, but in practice, the asymptotic solution is often an excellent approximation over several electron volts above $E_{\mathrm{F}}$, as is the case for Ir metal (see in the succeeding discussions). However, if the DOS is highly structured, $N_{\text {eh }}$ may not be linear in $\epsilon$ and the DS line shape will be a poor approximation above the threshold energy, as is the case for $\mathrm{IrO}_{2}$ (see in the succeeding discussions). ${ }^{16}$ In principle, it is possible to compute the line shape numerically if $N_{\text {eh }}$ is known with high fidelity. However, faithful computation of the electron hole pair excitation spectrum necessitates an extremely accurate DOS, ${ }^{16}$ which in turn requires detailed knowledge of the atomic structure. Unfortunately, we lack such information for the amorphous material used in this work. We can instead estimate deviations from the DS line shape using a one-electron picture by recognizing that, within this approximation, the structured DOS introduces additional "shake-up" satellites not predicted by the asymptotic theory. The positions of these satellites can be found using model systems. Thus, a fit model can be developed wherein the DS line shape is augmented with (Gaussian) shake-up satellites centered at their theoretically predicted binding energies. This approach offers a flexible and chemically intuitive means of linking theory and experiment for the speciation of Ir $4 \mathrm{f}$ spectra. 
To carry out this program, we require the initial and final states in the photoemission process of each material, states in the absence and presence of a core hole, respectively. The shake-up satellites are due to the excitation of an electron (near $E_{\mathrm{F}}$ ) in the absence of a core hole into an unoccupied level in the presence of a core hole and are governed by a monopole selection rule, giving $\Delta l=0$ within a central potential approximation. ${ }^{26}$ As such, we can determine the nature of potential shake-up satellites by examining the occupied 1-resolved DOS in the absence of a core hole and the unoccupied 1-resolved DOS in the vicinity of a core hole. To compute these DOSs, we projected the wave functions, obtained by way of density functional theory (DFT) with the Perdew, Burke, and Ernzerhof exchange and correlation potential, ${ }^{27}$ onto orthogonalized atomic wave functions, generating the projected density of states (PDOS) on the ground state and core-ionized iridium atoms.

All DFT calculations were performed with the Quantum ESPRESSO package ${ }^{28}$ using a kinetic energy cutoff of $50 \mathrm{Ry}$ and a charge density cutoff of $500 \mathrm{Ry}$. Spin polarization and scalar relativistic corrections were included. Ultrasoft pseudopotentials were taken from the PSLibrary. ${ }^{29}$ To compute the OK-edge spectra, two gauge-including augmented wave projectors were added to the $l=1$ channel of the oxygen pseudopotential. A k-point mesh equivalent to $(8 \times 8 \times 8)$ for the 24 -atom $\mathrm{IrO}_{2}$ cell (Figure 2.1) was used in all calculations along with Marzari-Vanderbilt cold smearing ${ }^{30}$ with a smearing parameter of $0.005 \mathrm{Ry}$.

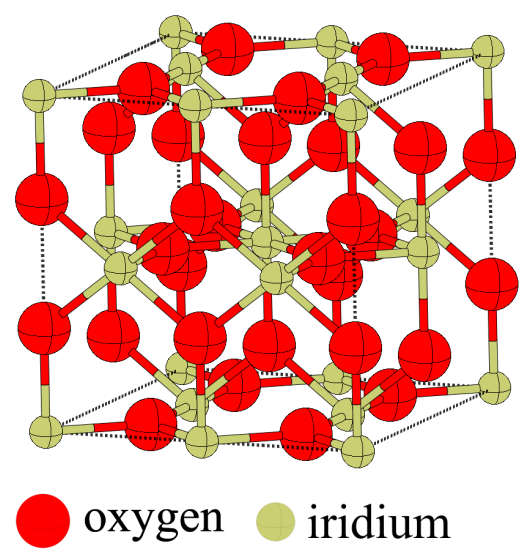

Figure 2.1: Twenty-four-atom supercell of $\mathrm{IrO}_{2}$ used for calculations.

Before calculating the spectroscopic properties, the rutile-type $\mathrm{IrO}_{2}$ cell volume was optimized, resulting in $\mathrm{a}=\mathrm{b}=4.56 \AA$ and $\mathrm{c}=3.19 \AA$ for the crystallographic unit cell, in good agreement with the $\mathrm{a}=\mathrm{b}=4.51 \AA$ and $\mathrm{c}=3.16 \AA$ measured experimentally. ${ }^{31}$ Ionic relaxations were performed until all components of the forces were less than $103 \mathrm{a}$.u., while the total change in energy was simultaneously less than $104 \mathrm{a}$.u. 
Spectroscopic properties were computed following the approach detailed in Jones et $a l .{ }^{32}$ Briefly, core level binding energies were computed using the $\triangle$ SCF (selfconsistent field) method to accurately recover initial and final state effects. ${ }^{33}$ The relative $\mathrm{O} 1 \mathrm{~s}$ binding energies computed with the $\triangle \mathrm{SCF}$ method were shifted to absolute binding energies using a reference calculation on a $(4 \times 4 \times 4)$ supercell of rutile-type $\mathrm{IrO}_{2}$, for which we took the measured O1s binding energy to be $530.0 \mathrm{eV}$. The relative Ir $4 \mathrm{f}$ binding energies were shifted to their absolute values using a reference calculation on a $(4 \times 4 \times 4)$ supercell of Ir metal, which we took to have an $\operatorname{Ir} 4 f_{7 / 2}$ binding energy of $60.8 \mathrm{eV}$. We verified that the relative binding energies in $\mathrm{IrO}_{2}$ were converged to better than $0.1 \mathrm{eV}$ with our computational setup, including supercell size.

OK-edge spectra were computed from Fermi's golden rule using the XSpectra package. ${ }^{34,35}$ Because powders were used in the experiments, we report the trace of the computed absorption cross section tensors. These computed spectra were convoluted using a Lorentzian with an energy-dependent linewidth, $\Gamma(E)=\Gamma_{0}+\Gamma(E)$, to account for lifetime broadening. The natural linewidth of oxygen, $0.14 \mathrm{eV}^{36}$ was used for $\Gamma_{0}$. The energy dependence was assumed to scale linearly, $\Gamma(E)=0.1\left(E-E_{\mathrm{F}}\right)$. This empirical energy dependence was chosen as it has previously been shown to be an effective approximation in a range of materials. ${ }^{32,37}$ Gaussian broadening was also included with a full width at half maximum (FWHM) of $0.6 \mathrm{eV}$ for calculations on rutile-type $\mathrm{IrO}_{2}$ and $0.8 \mathrm{eV}$ for the defective $\mathrm{IrO}_{x}$ spectra, where the increased $\mathrm{FWHM}$ of the latter is used to account for the reduced order in the amorphous samples. $E_{\mathrm{F}}$ of each computed spectrum was set to the computed O1s binding energy of the absorbing atom. With this method, the OK-edge spectrum of the crystalline bulk oxide, $\mathrm{IrO}_{2}$, was well reproduced without a core hole on the absorbing atom. As such, we computed all OK-edge spectra without a core hole on the absorbing atom. For a detailed discussion on the core hole effect in DFT, see, for instance, Mauchamp et al. ${ }^{38}$

\section{Results and discussion}

\section{Powder sample characterization}

A routine $\mathrm{XRD}$ characterization of the as-received iridium oxide powders revealed considerable differences in the XRD patterns (Figure 2.2). The Sigma-Aldrich powder exhibits the expected reflections of the rutile-type $\mathrm{IrO}_{2}$ structure; hence, we call it rutile-type $\mathrm{IrO}_{2}$. After calcination, the reflections are sharper and more symmetric due to crystallite growth and possibly a higher degree of stoichiometry. In contrast, as received, the AlfaAesar powder exhibits only minor Ir metal reflections. At the diffraction angles corresponding to rutile-type $\mathrm{IrO}_{2}$ reflections, the diffractogram of 
the AlfaAesar powder shows only slight, broad peaks. Therefore, the oxidic part of this powder is $\mathrm{X}$-ray amorphous, and we call the powder amorphous $\mathrm{IrO}_{\mathrm{x}}$. After calcination, sharp rutile-type $\mathrm{IrO}_{2}$ reflections evolve also in this powder, while the metallic reflections remain unaltered. Thus, only the formerly amorphous part of the sample crystallizes and is possibly further oxidized during the calcination process while the metal remains unchanged. Quantitative Rietveld analysis of the $\mathrm{IrO}_{2} / \mathrm{Ir}$ mixture after calcination yields an estimate of $2.4 \mathrm{wt} . \% \mathrm{Ir}$ metal in the formerly amorphous $\mathrm{IrO}_{\mathrm{x}}$ powder.

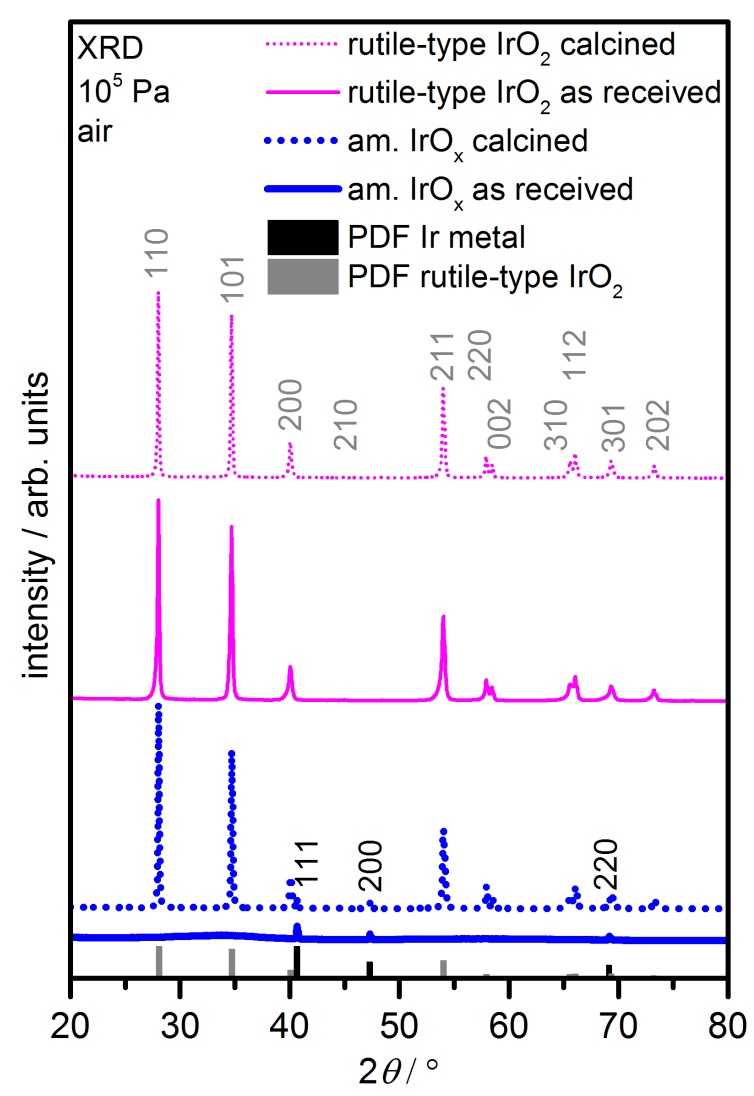

Figure 2.2: X-ray diffraction (XRD) patterns of the $\mathrm{IrO}_{2}$ and $\mathrm{IrO}_{\mathrm{x}}$ powders as received and after calcination at $1073 \mathrm{~K}$ in $10^{5} \mathrm{~Pa} \mathrm{O}_{2}$ for $50 \mathrm{~h}$. The initially amorphous powder shows as received broad peaks and crystallizes upon calcination. It contains a minor amount of Ir metal. The crystalline powder shows as received all reflections of rutile-type $\mathrm{IrO}_{2}$ and becomes more homogeneous upon calcination, which is seen by sharper, more symmetric reflections.

The different morphologies of the as-received samples are shown in the scanning electron microscopy images in Figure 2.3. The rutile-type $\mathrm{IrO}_{2}$ consists of parallelepiped-shaped particles of various sizes, while the amorphous $\mathrm{IrO}_{x}$ is less ordered and is composed of smaller, fluffy particles. EDX reveals the expected 1:2 atomic ratio of $\mathrm{Ir}: \mathrm{O}$ in the rutile-type $\mathrm{IrO}_{2}$, while an oxygen excess is observed for the amorphous $\mathrm{IrO}_{\mathrm{x}}$. In both samples, iron contamination of $\approx 1 \%$ was found. The correspond- 


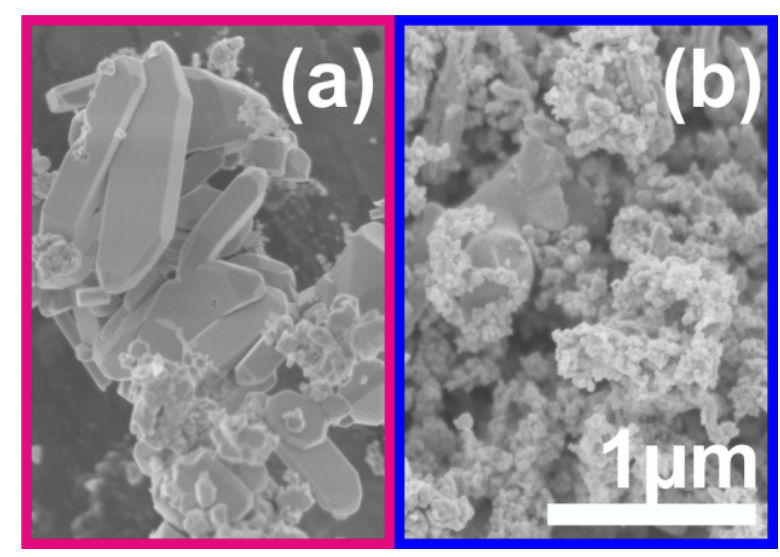

Figure 2.3: Scanning electron microscopy images of (a) the rutile-type $\mathrm{IrO}_{2}$ powder and (b) the amorphous $\operatorname{IrO}_{x}$ powder. The scale bar applies to both (a) and (b).

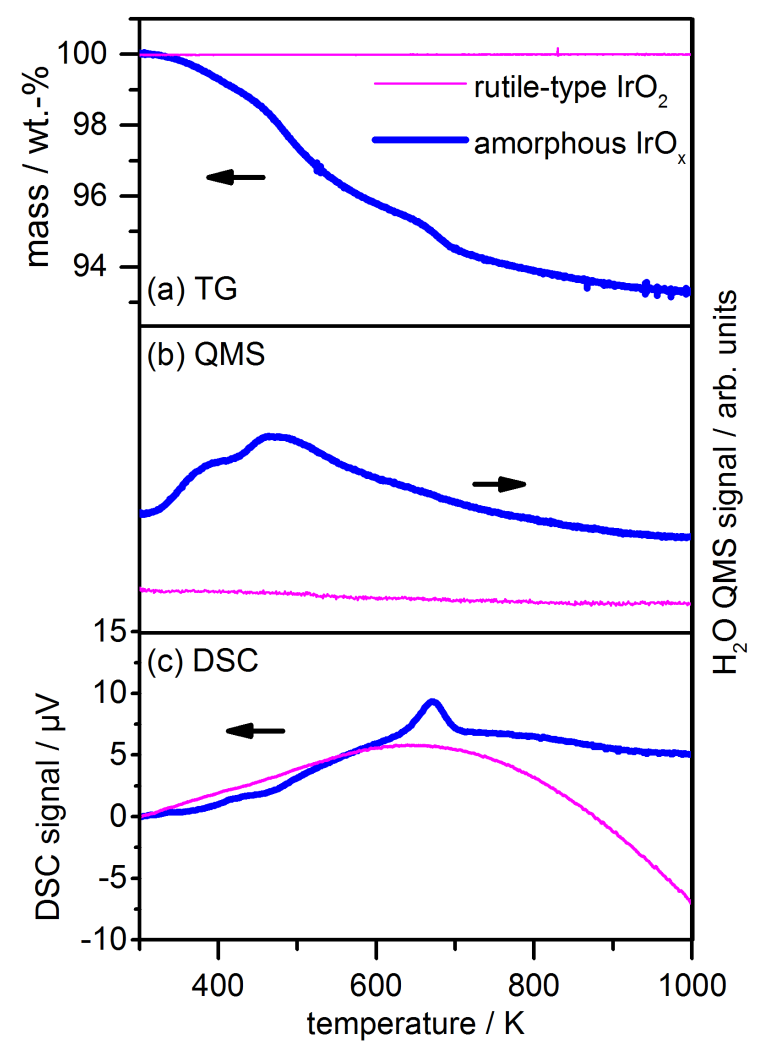

Figure 2.4: Thermogravimetry quadrupole mass spectrometry differential scanning calorimetry (TG-QMS-DSC). (a) The TG signal of the rutile-type $\mathrm{IrO}_{2}$ is constant over the entire temperature range, while the amorphous powder reduces its mass by 6 wt.\%. (b) Corresponding water $(m=18$ a. u.) QMS trace reveals that the weight loss of the amorphous powder is due to physisorbed and chemisorbed water loss. (c) DSC shows by an exothermic peak at $673 \mathrm{~K}$ that the amorphous powder crystallizes at this temperature.

ing BET surface area of the crystalline powder is considerably smaller $\left(2.1 \mathrm{~m}^{2} \mathrm{~g}^{-1}\right)$ than that of the amorphous $\operatorname{IrO}_{x}\left(33.3 \mathrm{~m}^{2} \mathrm{~g}^{-1}\right)$. 
The TG profile and the corresponding mass spectrum and DSC are shown in Figure 2.4. The rutile-type $\mathrm{IrO}_{2}$ powder does not show an obvious mass loss upon heating, and only a small amount of $\mathrm{CO}_{2}$ is released (not shown). In contrast, the amorphous $\mathrm{IrO}_{\mathrm{x}}$ loses $6 \mathrm{wt} . \%$ upon heating. The $\mathrm{H}_{2} \mathrm{O}$ quadrupole mass spectrometry trace shows that at around $400 \mathrm{~K} \approx 2 \mathrm{wt} . \%$ physisorbed water is released from $\mathrm{IrO}_{\mathrm{x}}$. From $\approx 500 \mathrm{~K}$ on, $\approx 4 \mathrm{wt} . \%$ chemisorbed water is released from the $\mathrm{IrO}_{\mathrm{x}}$ sample. The large amount of water contained in the amorphous $\mathrm{IrO}_{x}$ can account for the deviation from the nominal stoichiometry observed in EDX. An exothermic peak in DSC reveals that the $\mathrm{IrO}_{\mathrm{x}}$ sample crystallizes at $673 \mathrm{~K}$. The TPR profiles of both powders are shown in Figure 2.5. The two powders display differences in both their reduction profile and temperature. The rutile-type $\mathrm{IrO}_{2}$ is reduced at around $500 \mathrm{~K}$ in a temperature window of $\approx 75 \mathrm{~K}$, while the amorphous $\mathrm{IrO}_{x}$ is already reduced at $350 \mathrm{~K}$ in a temperature window of only $\approx 15 \mathrm{~K}$. Furthermore, the inset of Figure 2.5 reveals that the amorphous powder already adsorbs hydrogen during initial $\mathrm{H}_{2}$ exposure at room temperature, which needs to be taken into account when determining the overall $\mathrm{H}_{2}$ consumption of the amorphous $\mathrm{IrO}_{\mathrm{x}}$. Based on the total $\mathrm{H}_{2}$ consumption, the overall oxidation state of iridium in the two powders is calculated. For the rutile-type $\mathrm{IrO}_{2}$ powder, an Ir oxidation state of $4.1 \pm 0.1$ is obtained. This finding is in line with the EDX measurement and the expected formal Ir oxidation state of IV in stoichiometric $\mathrm{IrO}_{2}$. To account for only the oxygen-containing iridium species of the amorphous $\mathrm{IrO}_{\mathrm{x}}$, the metallic $\mathrm{Ir}$ and physisorbed water contents were subtracted prior to the oxidation state determination of the amorphous $\mathrm{IrO}_{x}$. In contrast to rutile-type $\mathrm{IrO}_{2}$, an $\mathrm{Ir}$ oxidation state of 3.6 \pm 0.1 is found for the oxygen-containing iridium species in the amorphous powder. Hence, the amorphous powder likely contains iridium-oxygen species with iridium in a formal oxidation state of less than IV, e.g. $\mathrm{Ir}^{\mathrm{III}}$, in addition to $\mathrm{Ir}^{\mathrm{IV}}$ species. We note that this presence of multiple iridium oxidation states has been argued to be crucial for enhanced OER activity. ${ }^{39,40}$

Indeed, OER activity assessment demonstrates that the amorphous sample is considerably more active than the rutile-type powder (Figure 2.6). The linear sweep voltammetry displays that the onset of the OER is at a lower potential, and the current density shows a steeper increase for amorphous $\mathrm{IrO}_{\mathrm{x}}$. And although the BET surface area of the amorphous powder is larger than that of the crystalline one (16x), it cannot explain the increased activity. It is then likely that the amorphous $\mathrm{IrO}_{x}$ possesses a surface termination that has an intrinsically higher OER activity than that of the surface species of rutile-type $\mathrm{IrO}_{2} \cdot{ }^{9}$

Our preliminary characterizations have revealed a variety of differences between these commercially available iridium oxide powders: crystalline versus amorphous, no water loss versus $6 \mathrm{wt} . \%$ water loss in TG, oxidation state 4.1 versus 3.6 from TPR 


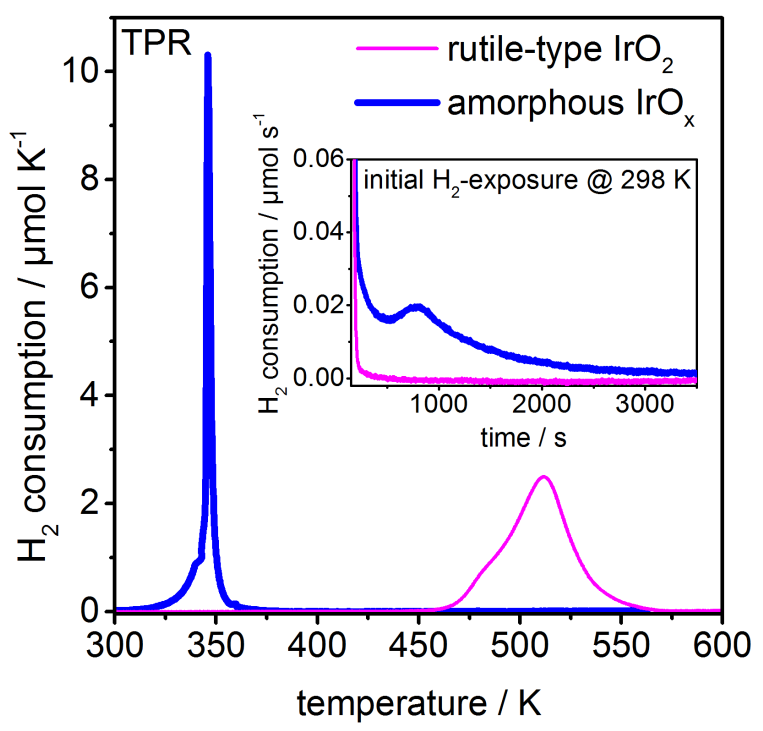

Figure 2.5: Temperature-programmed reduction (TPR) of amorphous $\mathrm{IrO}_{x}$ and rutile-type $\mathrm{IrO}_{2}$. The amorphous $\mathrm{IrO}_{x}$ already strongly adsorbs $\mathrm{H}_{2}$ at room temperature (inset) without releasing water (monitored by quadrupole mass spectrometry; not shown). Upon heating, the amorphous powder is reduced in a narrow temperature window at around $350 \mathrm{~K}$, while the rutile-type $\mathrm{IrO}_{2}$ is reduced in a broader temperature window at around $500 \mathrm{~K}$.

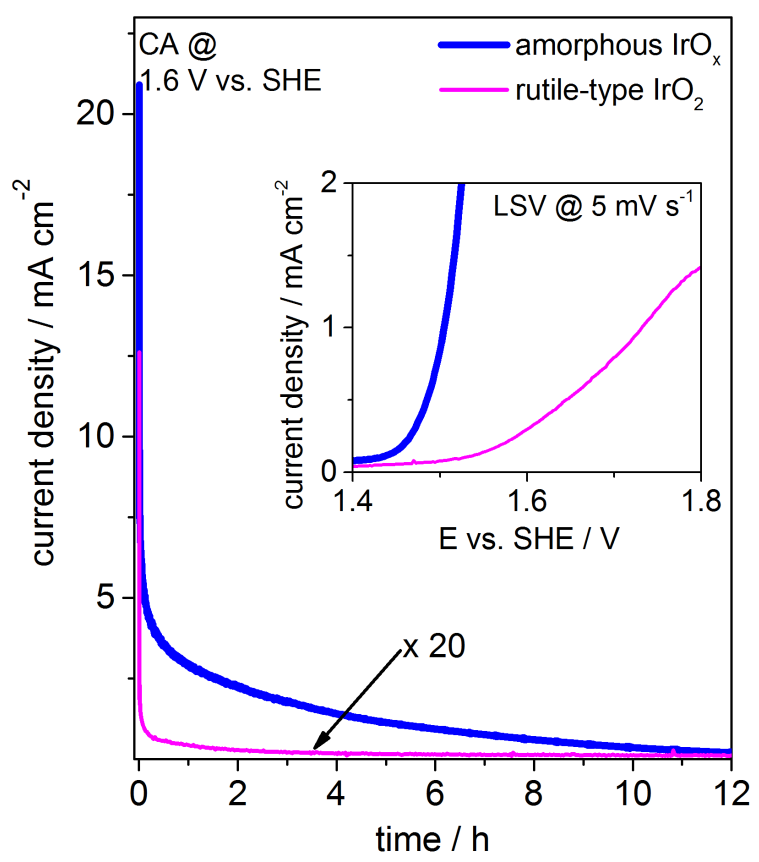

Figure 2.6: The linear sweep voltammetry (LSV) shows a much steeper and earlier OER onset for the amorphous $\mathrm{IrO}_{\mathrm{x}}$ than for rutile-type $\mathrm{IrO}_{2}$.

measurements, BET surface area $2.1 \mathrm{~m}^{2} \mathrm{~g}^{-1}$ versus $33.3 \mathrm{~m}^{2} \mathrm{~g}^{-1}$, low versus high catalytic activity. The difference in electrocatalytic performance is of significant interest as understanding which surface species are favorable in catalyzing the OER is a prerequisite to tailor iridium oxide-based catalysts with reduced precious metal contents. 
The electronic structure of these different iridium oxide powders may provide valuable insights into the nature of such active species. To characterize their electronic structures, we turn to XPS and NEXAFS.

\section{NAP-XPS and NEXAFS}

The most striking differences in the electronic structure of the two powders investigated in this work are found in their Ir $4 \mathrm{f}$ lines and OK-edges as illustrated in Figures 2.7 and 2.8. The $\mathrm{Ir} 4 \mathrm{f}$ line of the amorphous $\mathrm{IrO}_{\mathrm{x}}$ is significantly broader than that of rutile-type $\mathrm{IrO}_{2}$. The difference spectrum highlights that in the amorphous $\mathrm{IrO}_{x}$ intensity is shifted away from the positions of maximum intensity in the rutile-type $\mathrm{IrO}_{2}$ $(61.7 \mathrm{eV}$ and $64.7 \mathrm{eV})$ towards higher binding energy. The increased intensity at higher binding energy is indicative of the presence of additional oxygen-related species in the amorphous powder, which is corroborated by a comparison of the OK-edges of the two samples. The $\mathrm{OK}$-edge of the amorphous $\mathrm{IrO}_{\mathrm{x}}$ shows an additional resonance at $529 \mathrm{eV}$, while the intensity registered at $530 \mathrm{eV}$ is reduced compared with rutile-type $\mathrm{IrO}_{2}$.

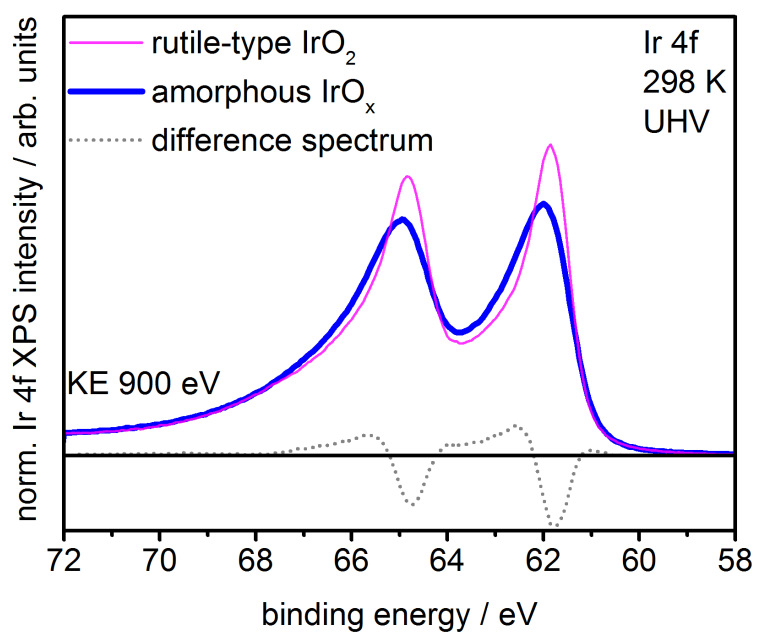

Figure 2.7: Comparison of the Ir $4 \mathrm{f}$ spectra of rutile-type $\mathrm{IrO}_{2}$ and amorphous $\mathrm{IrO}_{\mathrm{x}}$ normalized by area. The difference spectrum highlights that the amorphous $\mathrm{IrO}_{x}$ has less intensity where the rutile-type $\mathrm{IrO}_{2}$ main lines are located at and more intensity at higher binding energy.

Although multiple species appear to be present in the amorphous powder, a speciation of iridium oxides is not straightforward because of the peculiar Ir $4 \mathrm{f} \mathrm{line} \mathrm{shape} \mathrm{in}$ these materials. ${ }^{16}$ To advance toward an identification of the species contained in the catalytically more active amorphous iridium oxide, we make use of DFT calculations. By the combination of theory and experiment, we are able to further understand the 


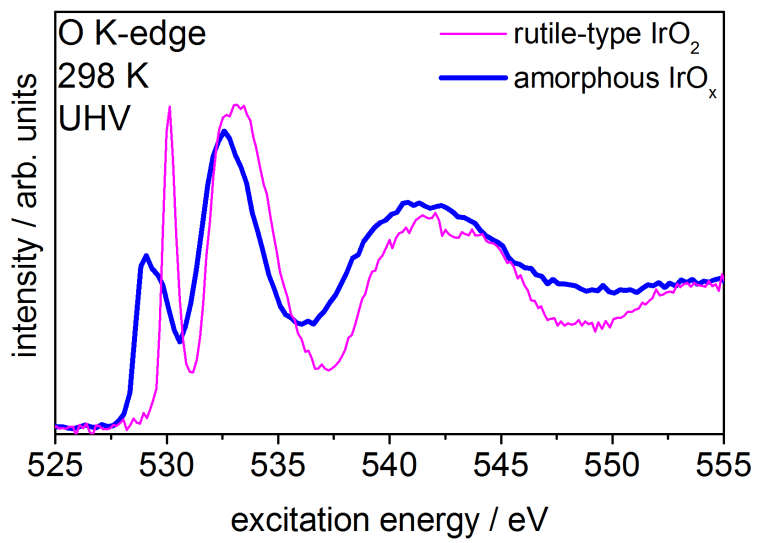

Figure 2.8: Comparison of the OK-edges of rutile-type $\mathrm{IrO}_{2}$ and amorphous $\mathrm{IrO}_{x}$. The amorphous $\mathrm{IrO}_{x}$ counts with an additional pre-edge feature at $529 \mathrm{eV}$ and less intensity at $530 \mathrm{eV}$, where rutile $\mathrm{IrO}_{2}$ has a sharp resonance. The broader resonance at $533 \mathrm{eV}$ in rutile-type $\mathrm{IrO}_{2}$ is shifted to slightly lower excitation energies in the amorphous $\mathrm{IrO}_{\mathrm{x}}$.

electronic structure of rutile-type $\mathrm{IrO}_{2}$ and amorphous $\mathrm{IrO}_{\mathrm{x}}$. However, before doing so, we first benchmark our approach in Ir metal.

\section{Single crystal Ir (111)}

As XRD had shown a minor amount of Ir metal contained in the amorphous $\operatorname{IrO}_{x}$, we found it prudent to investigate a metallic reference, for which we chose an Ir (111) single crystal. Ir single crystals have been widely studied by XPS. ${ }^{41,42}$ Hüfner et al. ${ }^{43}$ determined the DS parameter, $\alpha$, of Ir metal to be 0.12 , which enabled a fit of the asymmetric Ir $4 \mathrm{f}$ spectrum with a single contribution.

As a first test of our theoretical approach, we computed the PDOS of Ir metal in a 32-atom supercell with and without an Ir $4 \mathrm{f}$ core hole on a single excited atom. We found that the PDOS is only weakly structured and, therefore, the Ir $4 \mathrm{f}$ peak shape should be fit well by a standard DS function. To illustrate this point, consider that the most prominent shake-up satellites will come from transitions from occupied states at $E_{\mathrm{F}}$ to unoccupied states slightly above $E_{\mathrm{F}}$, as the energy dependence of the transition probability is $1 / \epsilon^{2}$, where $\epsilon$ is the excitation energy. Thus, because the states at $E_{\mathrm{F}}$ are principally $\mathrm{d}$ character and the shake-up process is governed by a monopole selection rule, we expect satellites will be due to transitions from occupied to unoccupied $\mathrm{d}$ states. Figure 2.9 shows the $d$ states on an Ir atom with a 4 f core hole, PDOS(d). Clearly, there is no significant structure in the PDOS(d). As a result, the final states are well represented by a flat DOS, and asymptotic theory is predicted to hold.

Figure 2.10 shows the Ir $4 \mathrm{f}$ line of an Ir (111) single crystal at three different probing depths. As expected from the theoretical calculations, good agreement between fit 


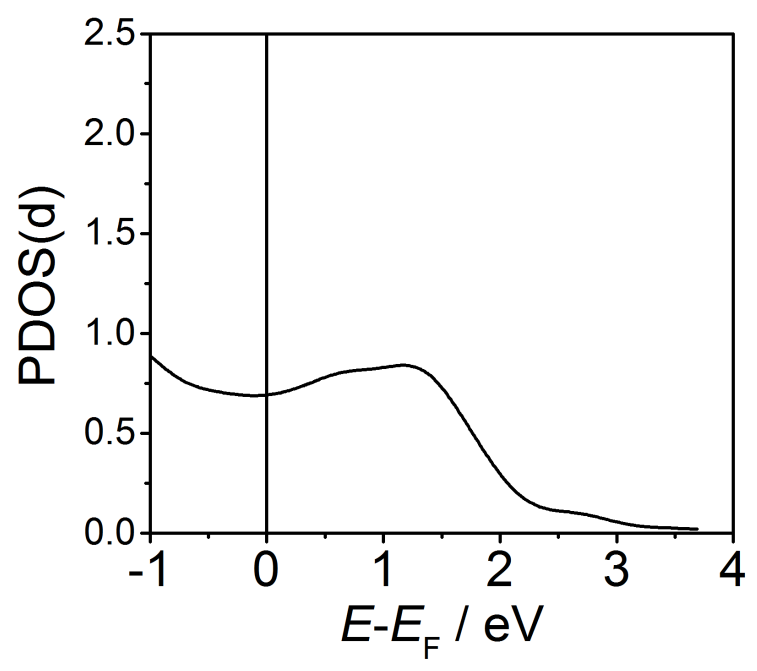

Figure 2.9: Calculated PDOS(d) of Ir metal in the presence of a $4 \mathrm{f}$ core hole. The PDOS shows no significant structuring.

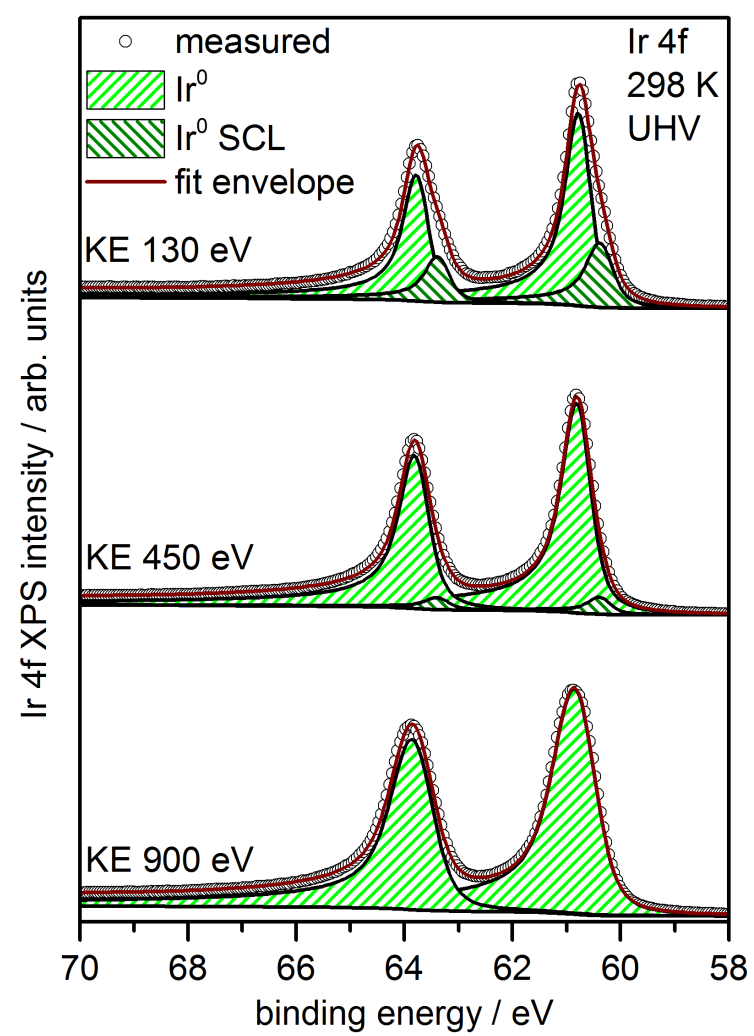

Figure 2.10: Ir 4f spectra with fits of an Ir (111) single crystal measured with three different kinetic energies (KE) of the photoelectrons. In the $130 \mathrm{eV}$ and $450 \mathrm{eV} \mathrm{KE}$ spectra, the surface core levels (SCL) of the single crystal termination are visible.

and experiment is obtained on the high binding energy side of the peak maximum by using a DS function $\left(\operatorname{Ir}^{0}\right)$ for the $\operatorname{Ir} 4 \mathrm{f}_{7 / 2}\left(\operatorname{Ir}_{4} \mathrm{f}_{5 / 2}\right)$ peak located at $60.8 \mathrm{eV}(63.8 \mathrm{eV})$. The DS parameter $\alpha$ found to best fit the spectra is 0.13 , which is in good agreement with the value determined by Hüfner et al. ${ }^{43}$ On the low binding energy side of the peak 
maximum, however, an additional peak ( $\left.\mathrm{Ir}^{0} \mathrm{SCL}\right)$ appears in the $130 \mathrm{eV}$ and $450 \mathrm{eV} \mathrm{KE}$ spectra due to the surface core level shift (SCLS) of the single crystal surface termination. This contribution is the most pronounced in the most surface-sensitive measurement and diminishes at larger probing depths. The appearance of such an SCLS has already been reported in the literature both by theory and experiment. ${ }^{42,44}$ These previous studies have found an SCLS of approximately $0.5 \mathrm{eV}$ on $\operatorname{Ir}$ (111) surfaces, slightly larger than the $0.4 \mathrm{eV}$ shift we observe. However, accurate measurement of the SCLS requires a dedicated effort to ensure the surface remains clean because even small amounts of contamination, e.g. adsorbed carbonaceous species, will modify or mask this additional contribution. ${ }^{42}$ We further note that the $\operatorname{Ir} 5 p_{1 / 2}$ peak is located at a binding energy of $\approx 63 \mathrm{eV}$ and completely buried by the Ir $4 \mathrm{f}$ signal. A determination of the theoretical cross-section ratio between the $5 \mathrm{p}_{1 / 2}$ and $4 \mathrm{f}$ peaks based on the calculations by Yeh and Lindau ${ }^{45}$ yields at most $2 \%$ for the photon energies employed in this work. Hence, the Ir $5 p_{1 / 2}$ has such a minor contribution to the recorded spectra that we omitted it in our fits in the interest of clarity. This omission will lead to a minor broadening of the Ir $4 \mathrm{f}$ peak contributions. The employed fit parameters are listed in Table 2.1. With higher excitation energy, the energy resolution of the beam line deteriorates. Therefore, the Gaussian contributions and the FWHM of the peaks are larger with increasing KE of the photoelectrons, and the peak maxima of the DS function are slightly shifted. Besides these adjustments, the fits remain unaltered for different probing depths.

Table 2.1: Fit parameters Ir (111) single crystal at three probing depths. KE, kinetic energy; SCL, surface core level; FWHM, full width at half maximum.

\begin{tabular}{|c|c|c|c|c|}
\hline $130 \mathrm{eV} \mathrm{KE}$ & $\begin{array}{l}\operatorname{Ir} 4 f_{7 / 2} \\
\operatorname{Ir}^{0}\end{array}$ & $\begin{array}{l}\operatorname{Ir}_{4} 4 f_{5 / 2} \\
\operatorname{Ir}^{0}\end{array}$ & $\begin{array}{l}\operatorname{Ir} 4 f_{7 / 2} \\
\operatorname{Ir}^{0} \text { SCL }\end{array}$ & $\begin{array}{l}\operatorname{Ir}^{4} f_{5 / 2} \\
\operatorname{Ir}^{0} \text { SCL }\end{array}$ \\
\hline \multirow[t]{2}{*}{ line shape } & $\mathrm{DS}(0.13,140)$ & $\mathrm{DS}(0.13,140)$ & $\mathrm{DS}(0.13,140)$ & $\mathrm{DS}(0.13,140)$ \\
\hline & SGL(100) & SGL(100) & SGL(100) & SGL(100) \\
\hline area / \% & 44.6 & 29.0 & 16.0 & 10.4 \\
\hline FWHM / eV & 0.5 & 0.5 & 0.6 & 0.5 \\
\hline binding energy / $\mathrm{eV}$ & 60.8 & 63.8 & 60.4 & 63.4 \\
\hline \multicolumn{5}{|l|}{$450 \mathrm{eV} \mathrm{KE}$} \\
\hline \multirow[t]{2}{*}{ line shape } & $\mathrm{DS}(0.13,160)$ & $\mathrm{DS}(0.13,160)$ & $\mathrm{DS}(0.13,160)$ & $\mathrm{DS}(0.13,160)$ \\
\hline & SGL(95) & SGL(95) & SGL(95) & SGL(95) \\
\hline area / \% & 53.6 & 40.2 & 3.6 & 2.7 \\
\hline FWHM / eV & 0.6 & 0.6 & 0.6 & 0.6 \\
\hline binding energy / $\mathrm{eV}$ & 60.8 & 63.8 & 60.4 & 63.4 \\
\hline \multicolumn{5}{|l|}{$900 \mathrm{eV} \mathrm{KE}$} \\
\hline \multirow[t]{2}{*}{ line shape } & $\mathrm{DS}(0.13,250)$ & $\mathrm{DS}(0.13,250)$ & & \\
\hline & SGL(90) & SGL(90) & & \\
\hline area / \% & 57.1 & 42.9 & & \\
\hline FWHM / eV & 0.9 & 0.9 & & \\
\hline binding energy / $\mathrm{eV}$ & 60.9 & 63.9 & & \\
\hline
\end{tabular}


Transferring this finding to our measured iridium oxides (Figure 2.7) shows that, although XRD documented the presence of metallic $\mathrm{Ir}$ in the amorphous $\mathrm{IrO}_{x}$ powder, neither of the two powders contains metallic Ir in the surface-near region as a peak at $60.8 \mathrm{eV}$ is absent in both cases.

\section{Rutile-type $\mathrm{IrO}_{2}$}

Rutile-type $\mathrm{IrO}_{2}$ is a metallic conductor, and therefore, an asymmetric line shape similar to the one of metallic Ir is expected. Nevertheless to date, we know of no example of a fit for rutile-type $\mathrm{IrO}_{2}$ that requires only one component. Earlier studies tried to explain this shortcoming by a compound such as $\mathrm{Ir}_{2} \mathrm{O}_{3}$ being present in commercially available $\mathrm{IrO}_{2}$ powders. ${ }^{13,46}$ Recently, Kahk et al. ${ }^{17}$ described the line shape based on the Kotani mode ${ }^{47}$ and proposed that the Ir $4 \mathrm{f}$ peak consists of a screened and an unscreened final state. Hence, they deconvoluted the rutile-type $\mathrm{IrO}_{2} \mathrm{Ir}_{4 f_{7 / 2}}$ line into two simple Gaussian-Lorentzian peaks. Importantly, their work showed that the uncommon line shape is inherent to the material and is not connected with stoichiometry deficiencies.

However, predicting the binding energies of a screened and an unscreened state can be cumbersome. For instance, Wertheim and Guggenheim ${ }^{16}$ predicted that the unscreened satellite would have a binding energy of $\approx 3 \mathrm{eV}$ above the main line, while we find a difference of $\approx 10 \mathrm{eV}$ between the computed final and initial state shifts, both of which are well above the values used in the Ir $4 \mathrm{f}$ deconvolution of Kahk et al. ${ }^{17}$ In an effort to develop a simple predictive model to capture the binding energy of the satellite peaks, we use our theoretical approach previously outlined.

To understand the nature of the $\mathrm{Ir} 4 \mathrm{f}$ spectrum in $\mathrm{IrO}_{2}$, we can again turn to the PDOS of an Ir atom with an Ir $4 \mathrm{f}$ core hole, which we computed in a $(4 \times 4 \times 4)$ supercell of $\mathrm{IrO}_{2}$. The resultant PDOS(d) of the Ir atom with a core hole is shown in Figure 2.11. As with Ir metal, we only show the $\mathrm{d}$ states because there are few $\mathrm{s}$ and $\mathrm{p}$ states near $E_{\mathrm{F}}$. Unlike the example of the metal, however, the $\mathrm{d}$ states on iridium in the oxide can be seen to be highly structured in the presence of a core hole. Inspection of the figure reveals that there is a strong narrow feature at $\approx 1 \mathrm{eV}$ above $E_{\mathrm{F}}$ in the final state PDOS(d). Excitation of Fermi energy electrons to this unoccupied state will lead to a shake-up satellite at $\approx 1 \mathrm{eV}$ above the main line in the $\mathrm{Ir} 4 \mathrm{f}$ spectrum of $\mathrm{IrO}_{2}$. Furthermore, the occupied states (inset in Figure 2.11) have a strong feature at $\approx 2 \mathrm{eV}$ below $E_{\mathrm{F}}$ because of localized nonbonding iridium d electrons. Excitation of these electrons into the unoccupied states at $1 \mathrm{eV}$ above $E_{\mathrm{F}}$ may lead to the appearance of a second satellite at $\approx 3 \mathrm{eV}$ above the main line in the Ir $4 \mathrm{f}$ spectrum. However, because the transition probability scales as $1 / \epsilon^{2}$ this second shake-up satellite, if visible, will be less prominent than the $\approx 1 \mathrm{eV}$ 
satellite. Thus, at a minimum, the $\mathrm{IrO}_{2} \mathrm{Ir} 4 \mathrm{f}$ line should then be fit using a standard DS function to capture the main line, for which our $\triangle$ SCF calculations predict a binding energy of $61.7 \mathrm{eV}$ for the $\operatorname{Ir} 4 \mathrm{f}_{7 / 2}$, and a Gaussian at $1 \mathrm{eV}$ higher binding energy to capture the primary shake-up satellite.

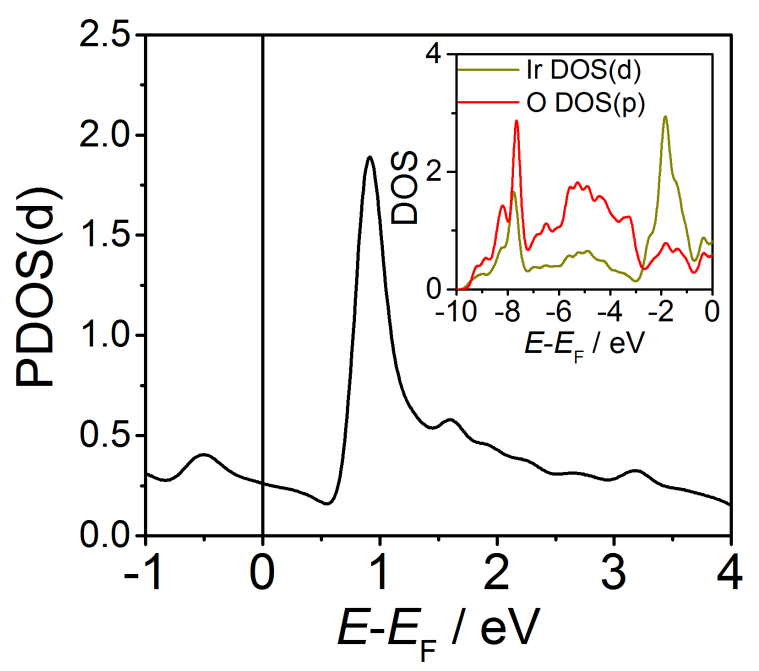

Figure 2.11: Calculated PDOS(d) of rutile-type $\mathrm{IrO}_{2}$ in the presence of a $4 \mathrm{f}$ core hole. The PDOS(d) shows a sharp peak at $1 \mathrm{eV}$ above $E_{\mathrm{F}}$ causing a shake-up satellite to appear $1 \mathrm{eV}$ above the main line of the $\operatorname{Ir} 4 \mathrm{f}$ spectrum due to excitation from electrons at $E_{\mathrm{F}}$ into these unoccupied states. The inset shows the calculated occupied DOS without a core hole. The DOS has a strong feature at $2 \mathrm{eV}$ binding energy. Excitation of electrons from these states into the unoccupied states $1 \mathrm{eV}$ above $E_{\mathrm{F}}$ may lead to a second shake-up satellite $3 \mathrm{eV}$ above the Ir $4 \mathrm{f}$ main line.

Based on our theoretical predictions, a least square fit of the rutile-type $\mathrm{IrO}_{2}$ Ir $4 \mathrm{f}$ spectra was carried out using one DS component $\left(\mathrm{Ir}^{\mathrm{IV}}\right)$ and one Gaussian satellite ( $\mathrm{Ir}^{\mathrm{IV}}$ sat1) for each, $\operatorname{Ir} 4 \mathrm{f}_{7 / 2}$ and $\operatorname{Ir} 4 \mathrm{f}_{5 / 2}$ (Figure 2.12). The fits at both probing depths give good agreement between the measured spectra and the fit envelopes except at a binding energy of $\approx 68 \mathrm{eV}$, where a minor deviation is observed. To obtain satisfactory agreement between the fit and measurement, the second satellite ( $\operatorname{Ir}^{\mathrm{IV}}$ sat2) of the $\operatorname{Ir} 4 \mathrm{f}_{5 / 2}$ peak at $\approx 3 \mathrm{eV}$ above the main line, stemming from the excitation from the localized nonbonding Ir d states $2 \mathrm{eV}$ below $E_{\mathrm{F}}$ into the unoccupied states at $1 \mathrm{eV}$ above $E_{\mathrm{F}}$ (Figure 2.11), needs to be added. As the corresponding second satellite of the $\operatorname{Ir} 4 \mathrm{f}_{7 / 2}$ peak is completely buried by the $\operatorname{Ir} 4 \mathrm{f}_{5 / 2}$ main line, it was not included in the fit. The need for an additional component at around $68 \mathrm{eV}$ has also been observed in previous fits of rutile-type $\mathrm{IrO}_{2} \cdot{ }^{48}$ All fit parameters are found in Table 2.2. In contrast to the Ir single crystal measurement, no SCLS is observed in the surface-sensitive measurement of the rutile-type $\mathrm{IrO}_{2}$ powder. The absence of the SCLS is potentially due to coverage of the surface by a carbonaceous layer. 
The predominance of a single phase of $\mathrm{IrO}_{2}$ is corroborated by the measured OKedge. As shown in Figure 2.13, the two pronounced resonances at $530 \mathrm{eV}$ and $533 \mathrm{eV}$ are in good agreement with our calculations of the phase-pure rutile-type $\mathrm{IrO}_{2} \mathrm{OK}$ edge, in which all oxygen and iridium are formally $\mathrm{O}^{\mathrm{II}-}$ and $\mathrm{Ir}^{\mathrm{IV}}$, respectively.

In summary, our combination of theory and experiment confirms that the peculiar Ir $4 \mathrm{f}$ line shape is inherent to rutile-type $\mathrm{IrO}_{2}$ and not connected to the presence of additional iridium species. In general, our approach offers a predictive means of identifying the presence of satellites and their binding energies for conductive materials with structured DOSs. For example, to further test our theoretical calculations, we computed the PDOS for $\mathrm{RuO}_{2}$ and $\mathrm{Cu}$ metal (not shown). For both materials, the presence $\left(\mathrm{RuO}_{2}\right)$ and the absence (Cu metal) of satellites was correctly predicted by a structured $\left(\mathrm{RuO}_{2}\right)$ and flat ( $\mathrm{Cu}$ metal) PDOS. Finally, for the material studied in this work, iridium oxide, our approach further enables speciation of $\operatorname{Ir} 4 \mathrm{f}$ spectra as shown in the succeeding discussions.

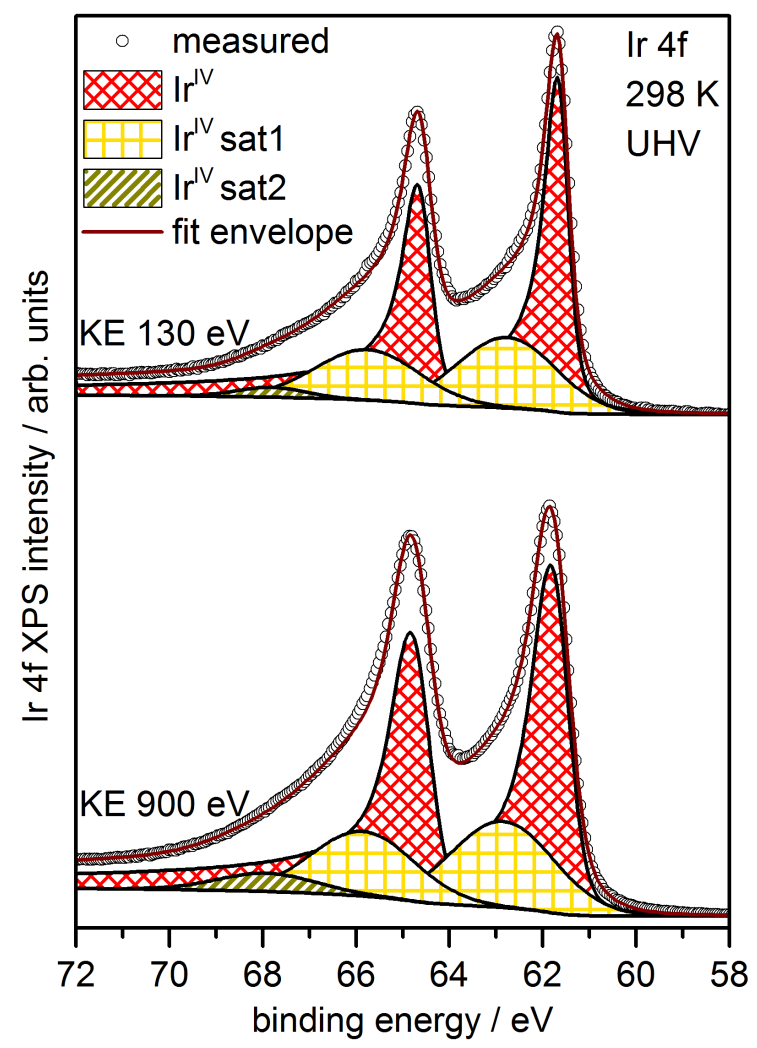

Figure 2.12: $\mathrm{Ir} 4 \mathrm{f}$ spectra of rutile-type $\mathrm{IrO}_{2}$ measured at two different kinetic energies (KE) and fit with a Doniach-Šnjić main line and Gaussian satellites based on theoretical findings. 
Table 2.2: Fit parameters rutile-type $\mathrm{IrO}_{2}$ at two probing depths. KE, kinetic energy; FWHM, full width at half maximum.

\begin{tabular}{|c|c|c|c|c|c|}
\hline $130 \mathrm{eV} \mathrm{KE}$ & $\begin{array}{l}\operatorname{Ir} 4 f_{7 / 2} \\
\operatorname{Ir}^{I V}\end{array}$ & $\begin{array}{l}\operatorname{Ir}_{4 f_{5 / 2}} \\
\operatorname{Ir}^{\mathrm{IV}}\end{array}$ & $\begin{array}{l}\operatorname{Ir} 4 f_{7 / 2} \\
\operatorname{Ir}^{1 V} \text { sat1 }\end{array}$ & $\begin{array}{l}\operatorname{Ir} 4 f_{5 / 2} \\
\operatorname{Ir}^{\mathrm{IV}} \text { sat1 }\end{array}$ & $\begin{array}{l}\operatorname{Ir} 4 f_{5 / 2} \\
\operatorname{Ir}{ }^{V} \text { sat2 }\end{array}$ \\
\hline \multirow[t]{2}{*}{ line shape } & $\mathrm{DS}(0.2,100)$ & $\mathrm{DS}(0.2,100)$ & GL(0) & GL(0) & GL(0) \\
\hline & SGL(65) & SGL(65) & & & \\
\hline area / \% & 44.6 & 34.8 & 11.2 & 8.4 & 1.1 \\
\hline FWHM / eV & 0.6 & 0.7 & 2.5 & 2.6 & 1.7 \\
\hline binding energy / eV & 61.7 & 64.7 & 62.8 & 65.8 & 67.8 \\
\hline \multicolumn{6}{|l|}{$900 \mathrm{eV} \mathrm{KE}$} \\
\hline \multirow[t]{2}{*}{ line shape } & $\mathrm{DS}(0.2,230)$ & $\mathrm{DS}(0.2,230)$ & GL(0) & GL(0) & GL(0) \\
\hline & SGL(55) & SGL(55) & & & \\
\hline area / \% & 44.1 & 35.7 & 10.4 & 7.8 & 2.1 \\
\hline FWHM / eV & 0.9 & 0.9 & 2.6 & 2.6 & 2.5 \\
\hline binding energy / eV & 61.8 & 64.8 & 62.9 & 65.9 & 67.9 \\
\hline
\end{tabular}

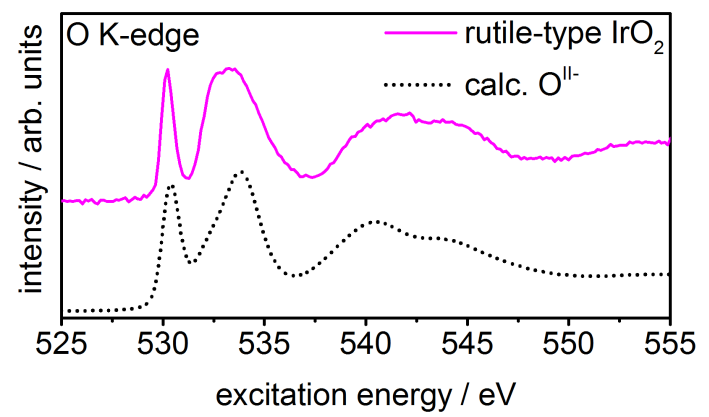

Figure 2.13: Measured (top) and calculated (bottom) OK-edge of rutile-type $\mathrm{IrO}_{2}$ containing solely $\mathrm{O}^{\mathrm{II}-}$ species.

\section{Amorphous $\mathrm{IrO}_{x}$}

As shown in Figure 2.7, the Ir 4f line shape of the amorphous powder is considerably broader than that of rutile-type $\mathrm{IrO}_{2}$ with additional intensity appearing at higher binding energy than that of the main lines of rutile-type $\mathrm{IrO}_{2}$. TPR shows that the oxidation state of the amorphous sample is likely a mixture between $\operatorname{Ir}^{\mathrm{III}}$ and $\mathrm{Ir}^{\mathrm{IV}}$; hence, it is tempting to assign this additional intensity to $\mathrm{Ir}^{\mathrm{III}}$. The assignment of a higher binding energy feature to a lower oxidation state is, at first, counterintuitive in XPS. Nevertheless, in the case of silver oxides, this phenomenon is well-known. ${ }^{49}$ In addition to this apparent defect in the cationic framework, the OK-edge of the amorphous $\mathrm{IrO}_{\mathrm{x}}$ has a pre-edge feature at $\approx 529 \mathrm{eV}$ (Figure 2.8), which hints at additional oxygen species. Such pre-edge features are commonly observed in other covalently bound oxides. By way of example, a pre-edge is observed in the OK-edge of superconducting cuprates upon doping due to the creation of holes in the $\mathrm{O} 2 \mathrm{p}$ orbitals (formally $\left.\mathrm{O}^{\mathrm{I}-}\right) \cdot{ }^{50,51}$ To test if these formally $\mathrm{Ir}^{\mathrm{III}}$ and $\mathrm{O}^{\mathrm{I}-}$ electronic defects can account for the additional features observed in the XPS and NEXAFS of $\mathrm{IrO}_{x}$ powders, we again turn to theory. 


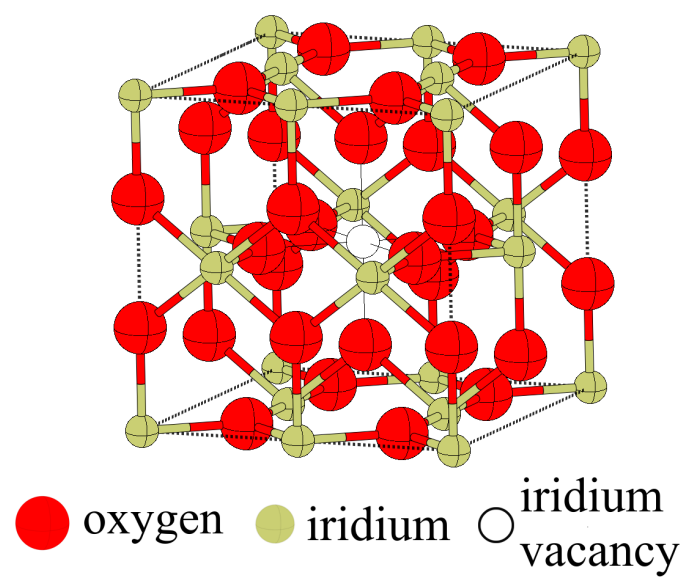

Figure 2.14: Supercell with Ir vacancy in the middle.
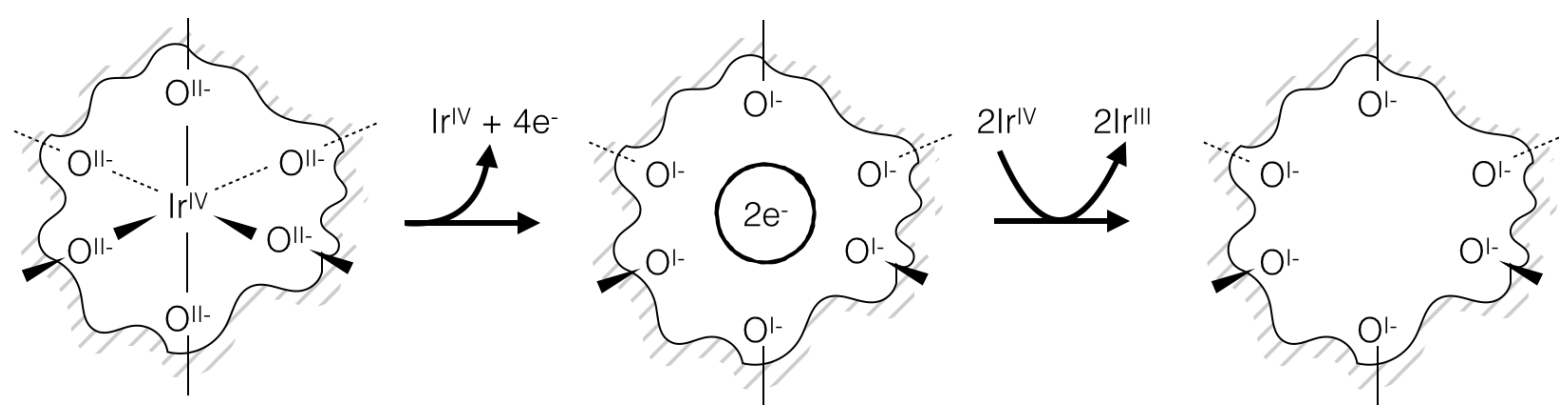

Figure 2.15: Scheme of transformations in the anionic and cationic framework upon the introduction of an Ir vacancy.

To study the possibility of $\mathrm{O} 2 \mathrm{p}$ hole and $\mathrm{Ir}^{\mathrm{III}}$ formation in $\mathrm{IrO}_{2}$, we used a 24-atom supercell of rutile-type $\mathrm{IrO}_{2}$ with a single Ir vacancy as a model system (Figure 2.14). As schematically outlined in Figure 2.15, introducing the Ir vacancy transforms the six formally $\mathrm{O}^{\mathrm{II}-}$ anions surrounding the vacancy to formally $\mathrm{O}^{\mathrm{I}-}$ species; the remaining $\mathrm{O}^{\mathrm{II}-}$ anions, those not in the neighborhood of the Ir vacancy, are comparatively unaltered. Thus, six electrons are transferred from $\mathrm{O}^{\mathrm{II}-}$ to the cationic framework. Of these six electrons, four are removed from the system by the $\operatorname{Ir}$ vacancy, $\operatorname{Ir}^{\mathrm{IV}}$ and $4 \mathrm{e}^{-}$. The remaining two electrons will then reduce neighboring $\mathrm{Ir}^{\mathrm{IV}}$ to $\mathrm{Ir}^{\mathrm{III}}$. In support of this view, our $\triangle$ SCF calculations reveal that Ir vacancy formation does lead to the appearance of species with an Ir $4 \mathrm{f}$ binding energy of $62.2 \mathrm{eV}$, which we attribute to the formally $\mathrm{Ir}^{\mathrm{III}}$ cations. Inspection of the PDOS(d) (not shown) reveals that these $\mathrm{Ir}^{\mathrm{III}}$ are expected to have a satellite at $\approx 1 \mathrm{eV}$ higher binding energy in the Ir $4 \mathrm{f}$ spectrum, leading to the fit shown in Figure 2.16. Evidence for the formally $\mathrm{O}^{\mathrm{I}-}$ species can be found in the computed $\mathrm{OK}$-edge spectrum, where the $\mathrm{O}^{\mathrm{I}-}$ species introduce a strong resonance at $\approx 529 \mathrm{eV}$ (Figure 2.17), in good agreement with experiment. 


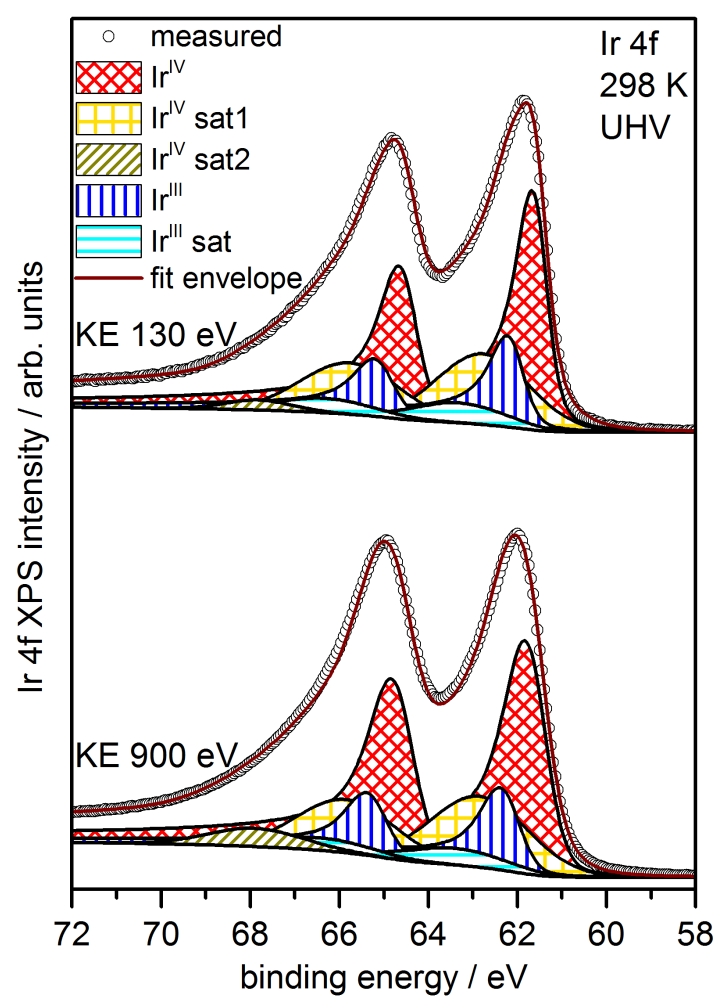

Figure 2.16: Ir $4 \mathrm{f}$ spectra of amorphous $\mathrm{IrO}_{x}$ measured at two different kinetic energies (KE) with $\mathrm{Ir}^{\mathrm{IV}}$ and $\mathrm{Ir}^{\mathrm{III}}$ Doniach-Šunjić main lines and corresponding Gaussian satellites based on theoretical findings.

Based on our theoretical findings, we developed a fit for the Ir $4 \mathrm{f}$ line of amorphous $\mathrm{IrO}_{\mathrm{x}}$, which is shown for two probing depths in Figure 2.16. We employed the established $\mathrm{Ir}^{\mathrm{IV}}$ fit functions from rutile-type $\mathrm{IrO}_{2}$ and added the $\mathrm{Ir}^{\mathrm{III}}$ components found in our model calculations with DS functions $(62.3 \mathrm{eV}$ and $65.3 \mathrm{eV})$ and corresponding Gaussian satellites. To account for a less regular order in the amorphous sample when compared with the crystalline one, we chose a higher FWHM value for the DS components of $\operatorname{Ir}^{\mathrm{IV}}$. The separation between $\operatorname{Ir}^{\mathrm{IV}}$ and $\mathrm{Ir}^{\mathrm{III}}$ leading to the best fit is $0.56 \mathrm{eV}$, which is slightly larger than what our calculations predict. When taking into account both the intensities of the main lines and corresponding satellites, the fits show that the subsurface region of the amorphous $\mathrm{IrO}_{x}$ powder contains roughly $80 \% \mathrm{Ir}^{\mathrm{IV}}$ and $20 \%$ Ir ${ }^{\mathrm{III}}$ species. At the outmost surface ( $130 \mathrm{eV}$ KE measurement), the defect density is slightly $(\approx 5 \%)$ larger. The fit parameters of all peaks and their intensities can be found in Table 2.3. 
Table 2.3: Fit parameters amorphous $\mathrm{IrO}_{x}$ as received at two probing depths. KE, kinetic energy; FWHM, full width at half maximum.

\begin{tabular}{|c|c|c|c|c|c|c|c|c|c|}
\hline $130 \mathrm{eV} \mathrm{KE}$ & $\begin{array}{l}\operatorname{Ir} 4 f_{7 / 2} \\
\operatorname{Ir}^{I V}\end{array}$ & $\begin{array}{l}\operatorname{Ir}_{4} f_{5 / 2} \\
\operatorname{Ir}^{I V}\end{array}$ & $\begin{array}{l}\operatorname{Ir} 4 f_{7 / 2} \\
\operatorname{Ir}^{1 V} \text { sat1 }\end{array}$ & $\begin{array}{l}\operatorname{Ir} 4 f_{5 / 2} \\
\operatorname{Ir}^{I V} \text { sat1 }\end{array}$ & $\begin{array}{l}\operatorname{Ir} 4 f_{5 / 2} \\
\operatorname{Ir}^{\mathrm{IV}} \text { sat2 }\end{array}$ & $\begin{array}{l}\operatorname{Ir} 4 f_{7 / 2} \\
\operatorname{Ir}^{\mathrm{III}}\end{array}$ & $\begin{array}{l}\operatorname{Ir} 4 \mathrm{f}_{5 / 2} \\
\operatorname{Ir}^{\mathrm{III}}\end{array}$ & $\begin{array}{l}\operatorname{Ir} 4 f_{7 / 2} \\
\operatorname{Ir}^{I I I} \text { sat1 }\end{array}$ & $\begin{array}{l}\operatorname{Ir} 4 f_{5 / 2} \\
\operatorname{Ir}^{I I I} \text { sat1 }\end{array}$ \\
\hline line shape & $\begin{array}{l}\mathrm{DS}(0.2,100) \\
\text { SGL(50) }\end{array}$ & $\begin{array}{l}\mathrm{DS}(0.2,100) \\
\mathrm{SGL}(50)\end{array}$ & GL(0) & GL(0) & GL(0) & $\begin{array}{l}\mathrm{DS}(0.2,100) \\
\mathrm{SGL}(50)\end{array}$ & $\begin{array}{l}\mathrm{DS}(0.2,100) \\
\mathrm{SGL}(50)\end{array}$ & GL(0) & GL(0) \\
\hline area / \% & 32.6 & 24.8 & 8.2 & 6.2 & 0.8 & 13.4 & 10.1 & 2.3 & 1.7 \\
\hline $\begin{array}{l}\text { FWHM / } \\
\mathrm{eV}\end{array}$ & 0.8 & 0.9 & 2.5 & 2.6 & 1.8 & 0.9 & 1 & 2.4 & 2.6 \\
\hline $\begin{array}{l}\text { binding en- } \\
\text { ergy / eV }\end{array}$ & 61.7 & 64.7 & 62.8 & 65.8 & 67.8 & 62.3 & 65.3 & 63.3 & 66.3 \\
\hline $900 \mathrm{eV} \mathrm{KE}$ & & & & & & & & & \\
\hline line shape & $\begin{array}{l}\mathrm{DS}(0.2,230) \\
\mathrm{SGL}(45)\end{array}$ & $\begin{array}{l}\mathrm{DS}(0.2,230) \\
\mathrm{SGL}(45)\end{array}$ & GL(0) & GL(0) & GL(0) & $\begin{array}{l}\mathrm{DS}(0.2,230) \\
\mathrm{SGL}(45)\end{array}$ & $\begin{array}{l}\mathrm{DS}(0.2,230) \\
\mathrm{SGL}(45)\end{array}$ & GL(0) & $\mathrm{GL}(0)$ \\
\hline area / \% & 33.8 & 27.4 & 7.9 & 6.0 & 2.0 & 10.9 & 8.8 & 1.9 & 1.4 \\
\hline $\begin{array}{l}\text { FWHM / } \\
\mathrm{eV}\end{array}$ & 1.1 & 1.1 & 2.6 & 2.6 & 2.5 & 1 & 1.1 & 2.6 & 2.6 \\
\hline $\begin{array}{l}\text { binding en- } \\
\text { ergy / eV }\end{array}$ & 61.8 & 64.8 & 62.9 & 65.9 & 67.9 & 62.4 & 65.4 & 63.4 & 66.4 \\
\hline
\end{tabular}

The OK-edge of the amorphous $\mathrm{IrO}_{\mathrm{x}}$ has resonances at $529 \mathrm{eV}$ and $530 \mathrm{eV}$. Hence, our calculations predict that it contains both formally $\mathrm{O}^{\mathrm{I}-}$ and $\mathrm{O}^{\mathrm{II}-}$ species. Because the $\mathrm{O} 2 \mathrm{p}$ hole is a localized defect, we can take a linear combination of the computed O K-edge spectra of $\mathrm{O}^{\mathrm{I}-}$ and $\mathrm{O}^{\mathrm{II}-}$ to estimate the amount of $\mathrm{O}^{\mathrm{I}-}$ in the probing depth of the experiment. Doing so, we find that a spectrum with approx. $40 \% \mathrm{O}^{\mathrm{I}-}$ and $60 \%$ $\mathrm{O}^{\mathrm{II}-}$ results in a good agreement between measurement and theory (Figure 2.17).

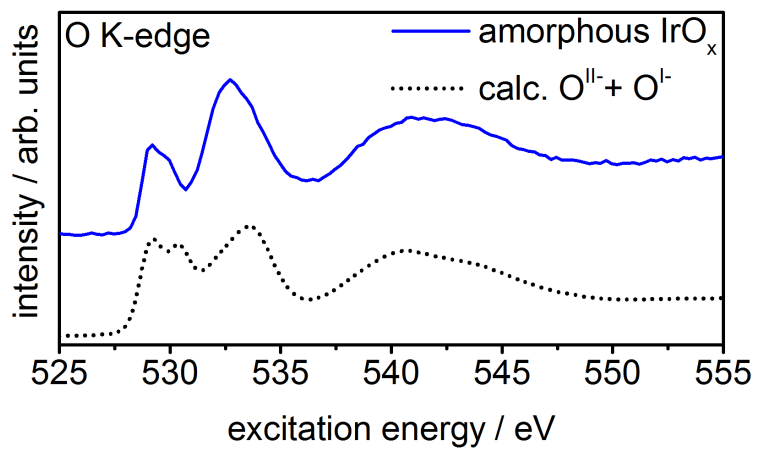

Figure 2.17: Measured (top) and calculated (bottom) OK-edge of amorphous $\mathrm{IrO}_{\mathrm{x}}$ containing both $\mathrm{O}^{\mathrm{I}-}$ and $\mathrm{O}^{\mathrm{II}-}$ species. For the calculated spectrum a share of $40 \%$ $\mathrm{O}^{\mathrm{I}-}$ yielded the best agreement with the measured spectrum.

In the model outlined in Figure 2.15, per each one $\mathrm{Ir}^{\mathrm{III}}$, three $\mathrm{O}^{\mathrm{I}-}$ are created. In line with this prediction, we find a higher concentration of electronic defects in the anionic than in the cationic framework of the amorphous material. A ratio as high as 1:3, though, does not result. This observation shows that as expected, the atomic structure of the amorphous $\mathrm{IrO}_{x}$ will be more complex than our model system. Nevertheless, the local defects in the atomic structure present in our model capture both kinds of 
electronic defects observed in the amorphous $\mathrm{IrO}_{x}$. Hence, these types of local defects are likely to be present in the amorphous framework. Furthermore, the calculations and fits based thereon allow us to estimate the defect concentrations in the surface and subsurface region, which are probed by XPS/NEXAFS and likely crucial for heterogeneous catalytic reactions.

\section{In situ XRD, XPS, and NEXAFS}

To substantiate our proposed fit for the amorphous $\mathrm{IrO}_{\mathrm{x}}$, we performed in situ XRD and XPS/NEXAFS heating experiments of the powder. In XRD, we already know that the initial pattern shows only broad peaks, compare Figure 2.2. Upon heating, the pattern in Figure 2.18 starts to show rutile-type $\mathrm{IrO}_{2}$ reflections at $623 \mathrm{~K}$. Crystallization appears to start roughly at this temperature under $10^{5} \mathrm{~Pa}$ in synthetic air as we had similarly observed in DSC. When heating to higher temperatures, the reflections become sharper hinting at a higher degree of homogeneity of the sample with increasing temperature.

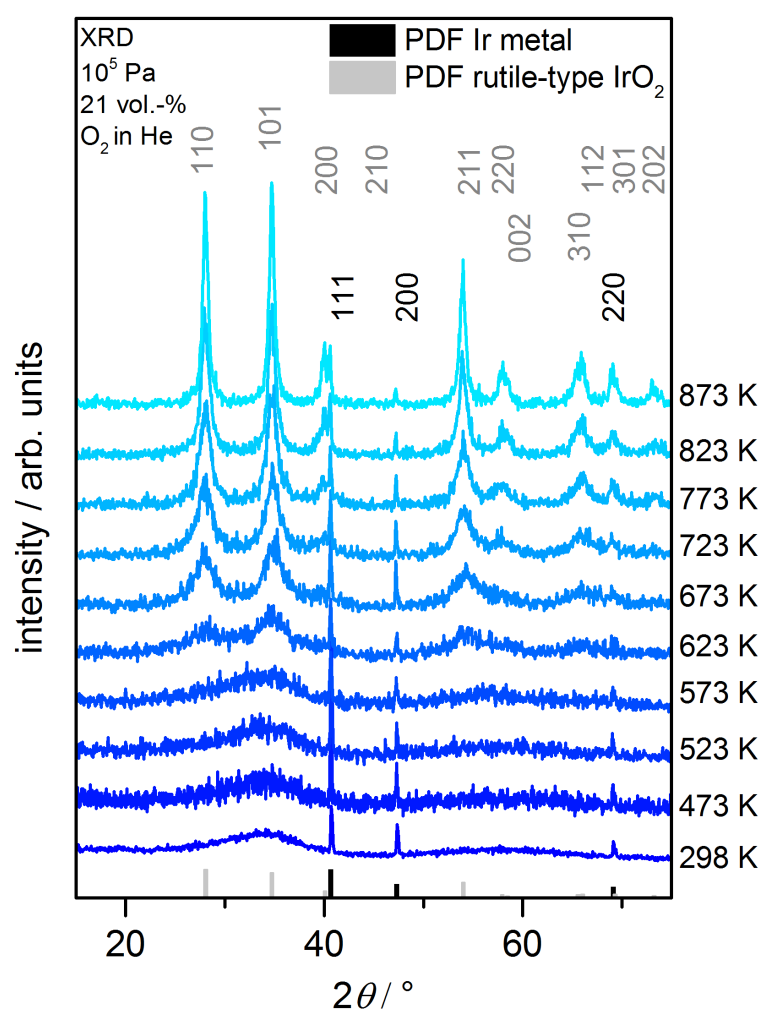

Figure 2.18: In situ XRD heating experiment at $10^{5} \mathrm{~Pa}$ in 21 vol. $\% \mathrm{O}_{2}$ of amorphous powder that initially does not show rutile-type $\mathrm{IrO}_{2}$ reflections but only metallic ones. Upon heating, rutile-type $\mathrm{IrO}_{2}$ reflections evolve.

In both XPS and NEXAFS, the changes in the spectra upon heating in $25 \mathrm{~Pa}_{2}$ are obvious (Figures 2.19 and 2.20). The contributions of $\operatorname{Ir}^{\mathrm{III}}$ to the $\mathrm{Ir} 4 \mathrm{f}$ line at $62.3 \mathrm{eV}$ 


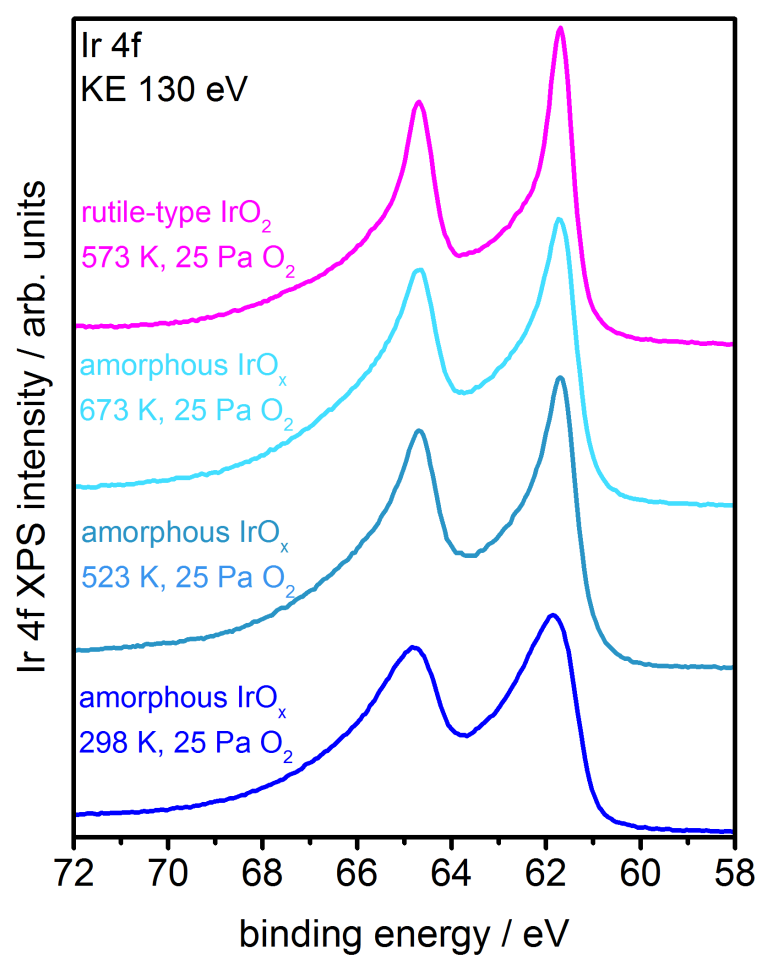

Figure 2.19: In situ XPS heating experiment of the amorphous powder. The intensity at higher binding energy than the main line of $\mathrm{IrO}_{2}$ is reduced with increasing temperature. A comparison with the rutile-type $\mathrm{IrO}_{2} \mathrm{Ir} 4 \mathrm{f}$ spectrum and the measurement of the amorphous $\mathrm{IrO}_{x}$ at $673 \mathrm{~K}$ still shows a slightly broader spectrum.

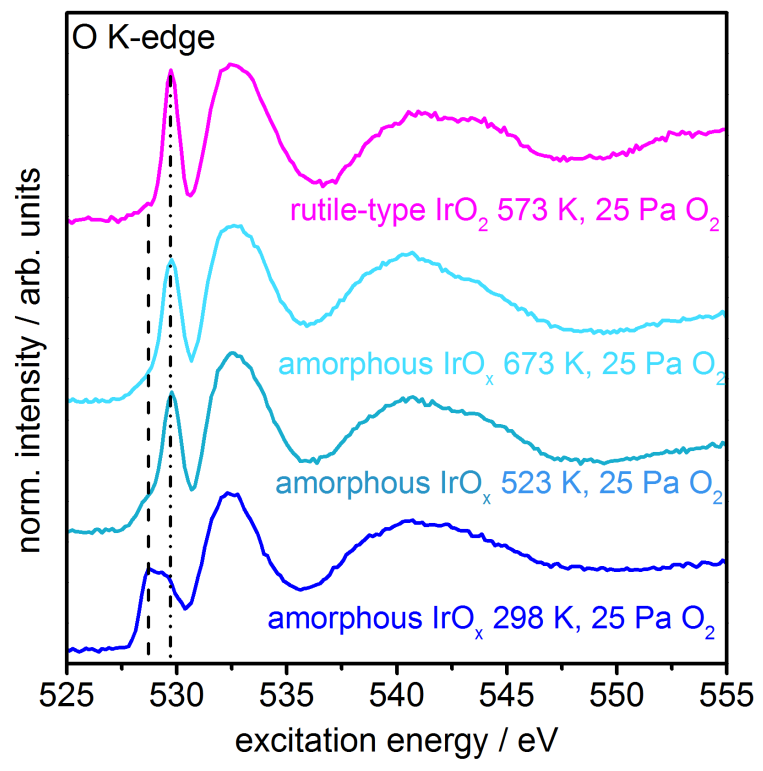

Figure 2.20: In situ NEXAFS heating experiment of the amorphous $\mathrm{IrO}_{\mathrm{x}}$ powder. Spectra are corrected by the $\mathrm{O}_{2}$ gas phase transmission. The intensity of the resonance at $529 \mathrm{eV}$ is reduced with increasing temperature. A comparison with the rutile-type $\mathrm{IrO}_{2} \mathrm{O}$ K-edge still shows that a slightly larger contribution of the $529 \mathrm{eV}$ resonance is still present at $673 \mathrm{~K}$. 


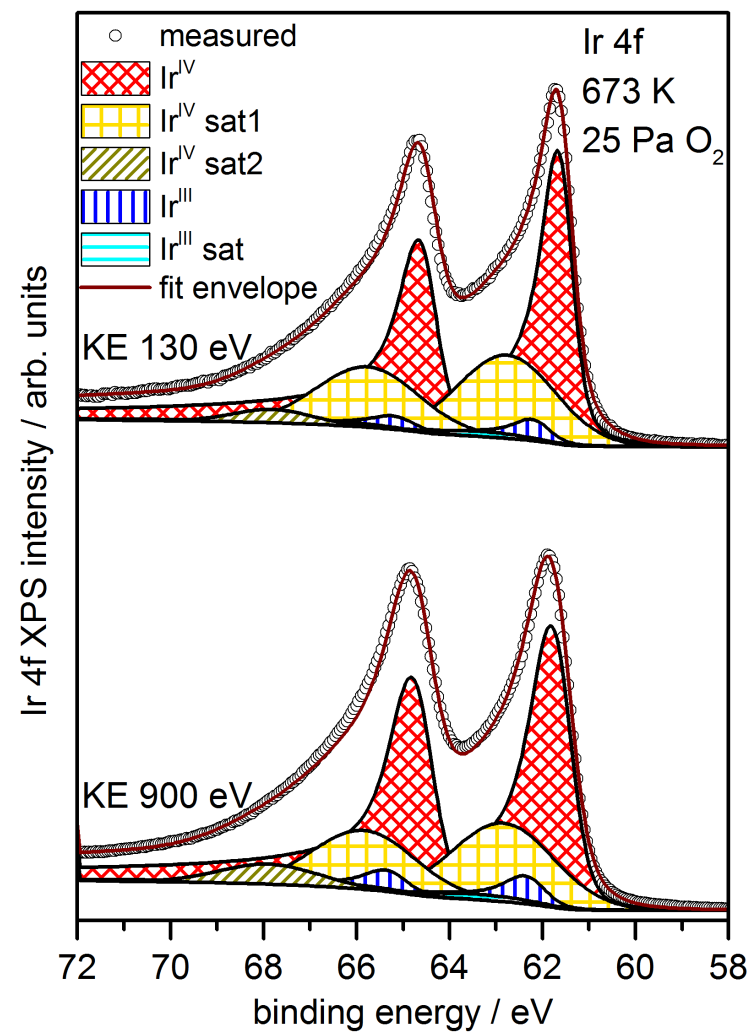

Figure 2.21: $\mathrm{Ir} 4 \mathrm{f}$ spectra of amorphous $\mathrm{IrO}_{\mathrm{x}}$ measured at $673 \mathrm{~K}$ in $25 \mathrm{~Pa} \mathrm{O}_{2}$ at two different kinetic energies (KE) with theory-based fit models. Compared with the measurement at room temperature, the $\mathrm{Ir}^{\mathrm{III}}$ component is decreased.

and $65.3 \mathrm{eV}$ are reduced with a concomitant decrease in the intensity of the $529 \mathrm{eV}$ component in the $\mathrm{OK}$-edge and an increase in the intensity of the resonance at $530 \mathrm{eV}$. To remove the distortion of the NEXAFS spectra by photon absorption in the gas phase, the spectra shown in Figure 2.20 were reconstructed by taking into account the $\mathrm{O}_{2}$ gas phase transmission as described in detail in Hävecker et al. ${ }^{22}$ At $673 \mathrm{~K}$, a comparison with spectra of phase pure rutile-type $\mathrm{IrO}_{2}$ still shows discrepancies, which are likely a result of the incomplete oxidation and crystallization under the applied conditions (Figure 2.20). This view is further supported by the aforementioned observation from in situ XRD that heating to $673 \mathrm{~K}$ might not be sufficient to obtain a homogeneous sample (Figure 2.18). Therefore, a fraction of the structural and electronic defects might still be present in the $\mathrm{IrO}_{x}$ sample after heating.

The continued presence of electronic defects in the cationic framework is corroborated by a fit of the Ir $4 \mathrm{f}$ region. Figure 2.21 shows the fit of the Ir $4 \mathrm{f}$ line measured at $673 \mathrm{~K}$ in $\mathrm{O}_{2}$ based on the model developed in this section. Note that the area ratio between the DS lines and the corresponding satellites is fixed to a constant value to ensure comparability between different fits. Fit parameters are listed in Table 2.4. As anticipated, the contribution of $\mathrm{Ir}^{\mathrm{III}}$ is smaller than for the sample in the as-received state 
(7\% vs. $20 \%$ ) but has still not completely vanished. The $\operatorname{Ir}^{\mathrm{IV}}$ component increases and, as a result of partial crystallization, is more ordered than in the initial state, which is reflected by a slightly decreased FWHM even though measured at an elevated temperature. Also for this state of the powder, good agreement is obtained for the measured spectra and the fit using our newly introduced model.

Table 2.4: Fit parameters amorphous $\mathrm{IrO}_{\mathrm{x}}$ at $673 \mathrm{~K}$ in $25 \mathrm{~Pa} \mathrm{O}_{2}$ at two probing depths. KE, kinetic energy; FWHM, full width at half maximum.

\begin{tabular}{|c|c|c|c|c|c|c|c|c|c|}
\hline $130 \mathrm{eV} \mathrm{KE}$ & $\begin{array}{l}\operatorname{Ir} 4 f_{7 / 2} \\
\operatorname{Ir}^{I V}\end{array}$ & $\begin{array}{l}\operatorname{Ir} 4 f_{5 / 2} \\
\operatorname{Ir}^{I V}\end{array}$ & $\begin{array}{l}\mathrm{Ir} 4 \mathrm{f}_{7 / 2} \\
\mathrm{Ir}^{\mathrm{IV}} \text { sat1 }\end{array}$ & $\begin{array}{l}\operatorname{Ir} 4 f_{5 / 2} \\
\operatorname{Ir}^{I V} \text { sat1 }\end{array}$ & $\begin{array}{l}\operatorname{Ir} 4 f_{5 / 2} \\
\operatorname{Ir}^{I V} \text { sat2 }\end{array}$ & $\begin{array}{l}\operatorname{Ir} 4 f_{7 / 2} \\
\operatorname{Ir}^{\mathrm{III}}\end{array}$ & $\begin{array}{l}\operatorname{Ir} 4 f_{5 / 2} \\
\operatorname{Ir}^{I I I}\end{array}$ & $\begin{array}{l}\operatorname{Ir} 4 f_{7 / 2} \\
\operatorname{Ir}^{I I I} \text { sat1 }\end{array}$ & $\begin{array}{l}\operatorname{Ir}_{4 f_{5 / 2}} \\
\mathrm{Ir}^{\mathrm{III}} \text { sat1 }\end{array}$ \\
\hline \multirow[t]{2}{*}{ line shape } & $\mathrm{DS}(0.2,100)$ & $\mathrm{DS}(0.2,100)$ & $\mathrm{GL}(0)$ & $\mathrm{GL}(0)$ & $\mathrm{GL}(0)$ & $\mathrm{DS}(0.2,100)$ & $\mathrm{DS}(0.2,100)$ & $\mathrm{GL}(0)$ & $\mathrm{GL}(0)$ \\
\hline & SGL(55) & SGL(55) & & & & SGL(55) & SGL(55) & & \\
\hline area / \% & 41.2 & 32.1 & 10.3 & 7.9 & 1.3 & 3.5 & 2.6 & 0.6 & 0.4 \\
\hline $\begin{array}{l}\text { FWHM / } \\
\mathrm{eV}\end{array}$ & 0.8 & 0.9 & 2.5 & 2.6 & 2 & 0.9 & 1 & 2.3 & 2.4 \\
\hline $\begin{array}{l}\text { binding en- } \\
\text { ergy / eV }\end{array}$ & 61.7 & 64.7 & 62.8 & 65.8 & 67.8 & 62.3 & 65.3 & 63.3 & 66.3 \\
\hline \multicolumn{10}{|l|}{$900 \mathrm{eV} \mathrm{KE}$} \\
\hline line shape & $\mathrm{DS}(0.2,230)$ & $\mathrm{DS}(0.2,230)$ & GL(0) & GL(0) & GL(0) & $\mathrm{DS}(0.2,230)$ & $\mathrm{DS}(0.2,230)$ & GL(0) & GL(0) \\
\hline & SGL(50) & SGL(50) & & & & SGL(50) & SGL(50) & & \\
\hline area / \% & 40.2 & 32.6 & 9.5 & 7.1 & 2.3 & 4.0 & 3.2 & 0.7 & 0.5 \\
\hline $\begin{array}{l}\text { FWHM / } \\
\mathrm{eV}\end{array}$ & 1 & 1.1 & 2.6 & 2.6 & 2.5 & 1 & 1.1 & 2.6 & 2.6 \\
\hline $\begin{array}{l}\text { binding en- } \\
\text { ergy / eV }\end{array}$ & 61.8 & 64.8 & 62.9 & 65.9 & 67.9 & 62.4 & 65.4 & 63.4 & 66.4 \\
\hline
\end{tabular}

\section{Conclusion}

In conclusion, we describe the electronic structure of Ir metal, rutile-type $\mathrm{IrO}_{2}$, and an amorphous $\mathrm{IrO}_{\mathrm{x}}$. We confirm that the line shape of Ir metal is well-described by a simple DS function. For iridium oxides, however, a shake-up satellite is identified at $1 \mathrm{eV}$ above the main Ir $4 \mathrm{f}$ line. This satellite accounts for the peculiar line shape of phasepure rutile-type $\mathrm{IrO}_{2}$. As we have probed our samples at different information depths, we can exclude that the observed phenomena are solely due to surface effects but are also present in the subsurface region. Our theoretical models explain formerly unidentified features observed in the OK-edge and the $\mathrm{Ir} 4 \mathrm{f}$ line of amorphous $\mathrm{IrO}_{\mathrm{x}} \cdot \mathrm{O} 2 \mathrm{p}$ hole states, which are formally $\mathrm{O}^{\mathrm{I}-}$, cause a resonance at $529 \mathrm{eV}$ in the OK-edge NEXAFS. A compensatory IrIII species exhibits a reverse binding energy shift in XPS. This reverse shift is responsible for the increased intensity in the $\mathrm{Ir} 4 \mathrm{f}$ line at higher binding energy than the rutile-type $\mathrm{IrO}_{2} \mathrm{Ir} 4 \mathrm{f}$ signal. Hence, our calculations show that caution is required when assigning oxidation states based solely on binding energy shifts. Finally, our investigation enables an estimation of the concentration of the electronic 
defects in the anionic and cationic framework of the more active catalyst studied in this work. These electronic defects may account for the increased electrocatalytic activity observed in such amorphous iridium oxide systems. For a deeper understanding of how such highly defective termination layers evolve on surfaces under the influence of applied potentials, XPS and NEXAFS investigations of oxygen-evolving iridium catalysts are needed.

\section{Supplementary Information ${ }^{\mathbb{I}}$}

\section{Calculated PDOS and measured valence band spectra}

To further investigate the differences in the electronic structure of rutile-type $\mathrm{IrO}_{2}$, amorphous $\mathrm{IrO}_{x}$, and the contained $\mathrm{O}^{\mathrm{I}-}$ and $\mathrm{O}^{\mathrm{II}-}$ species, we explored the occupied electronic states of the materials near the Fermi energy $\left(E_{\mathrm{F}}\right)$ by comparing measured valence band (VB) spectra with the computed projected density of states (PDOS). Though the PDOS and VB spectra are not exactly comparable because of, for instance, matrix element effects and lifetime broadening, the main peak positions should still be in good agreement. By using a projected density of states, it is possible to extract information about which element gives rise to the states associated with a given peak, making a combination of the measured VB spectra and the computed PDOS an excellent complement to the OK-edge NEXAFS, which effectively measures the unoccupied part of the projected Op states, PDOS(p).

The calculations were performed using the cells shown in Figures 2.1 and 2.14. The geometry of the three iridium atoms surrounding one oxygen atom in the defect-free $\mathrm{IrO}_{2}$ cell is shown in Figure S2.7.1. In the cell that contains an Ir vacancy, for six of the oxygen atoms one of these surrounding iridium atoms is missing.

Figure S2.7.2 shows a comparison of the PDOS of only the O $2 p_{y}$ and all O $2 p$ orbitals of single $\mathrm{O}^{\mathrm{I}-}$ and $\mathrm{O}^{\mathrm{II}-}$ species, respectively. The $\mathrm{O} 2 \mathrm{p}_{\mathrm{y}}$ orbitals are those mainly involved in $\pi$-bonding and -anti-bonding as may be inferred from Figure S2.7.1. Their PDOS is shown separately since we observe a shift of these states towards more positive energies, i. e. a deoccupation, when comparing $\mathrm{O}^{\mathrm{I}-}$ and $\mathrm{O}^{\mathrm{II}-}$. This deoccupation is also reflected by an increased splitting of the overall PDOS of the $\mathrm{O} 2 \mathrm{p}$ states near $E_{\mathrm{F}}$ of $\mathrm{O}^{\mathrm{I}-}$ when compared to $\mathrm{O}^{\mathrm{II}-}$.

\footnotetext{
IT This section was partly reproduced from the Supplementary Information to Pfeifer, V., Jones, T. E., Velasco Vélez, J. J., Massué, C., Greiner, M. T., Arrigo, R., Teschner, D., Girgsdies, F., Scherzer, M., Allan, J., Hashagen, M., Weinberg, G., Piccinin, S., Hävecker, M., Knop-Gericke, A., and Schlögl, R. 2016 The electronic structure of iridium oxide electrodes active in water splitting. Phys. Chem. Chem. Phys., 18, 2292-2296, doi: 10.1039/C5CP06997A

with permission from the PCCP Owner Societies.
} 

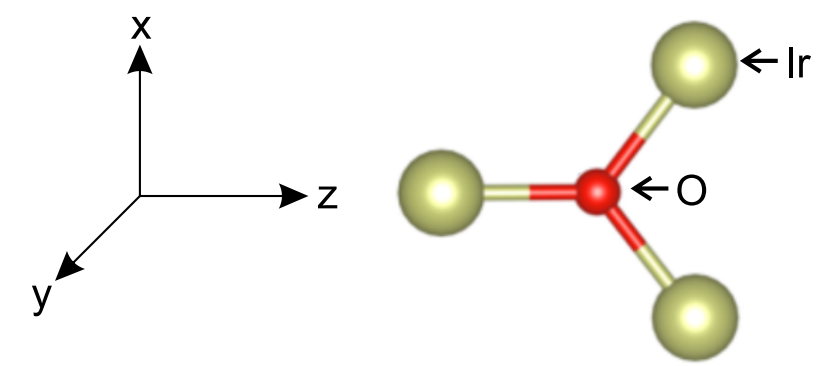

Figure S2.7.1: Geometry of the three iridium atoms surrounding one oxygen atom in the defect free $\mathrm{IrO}_{2}$ cell. The $\mathrm{Ir}$ and $\mathrm{O}$ atoms are in the $\mathrm{xz}$-plane
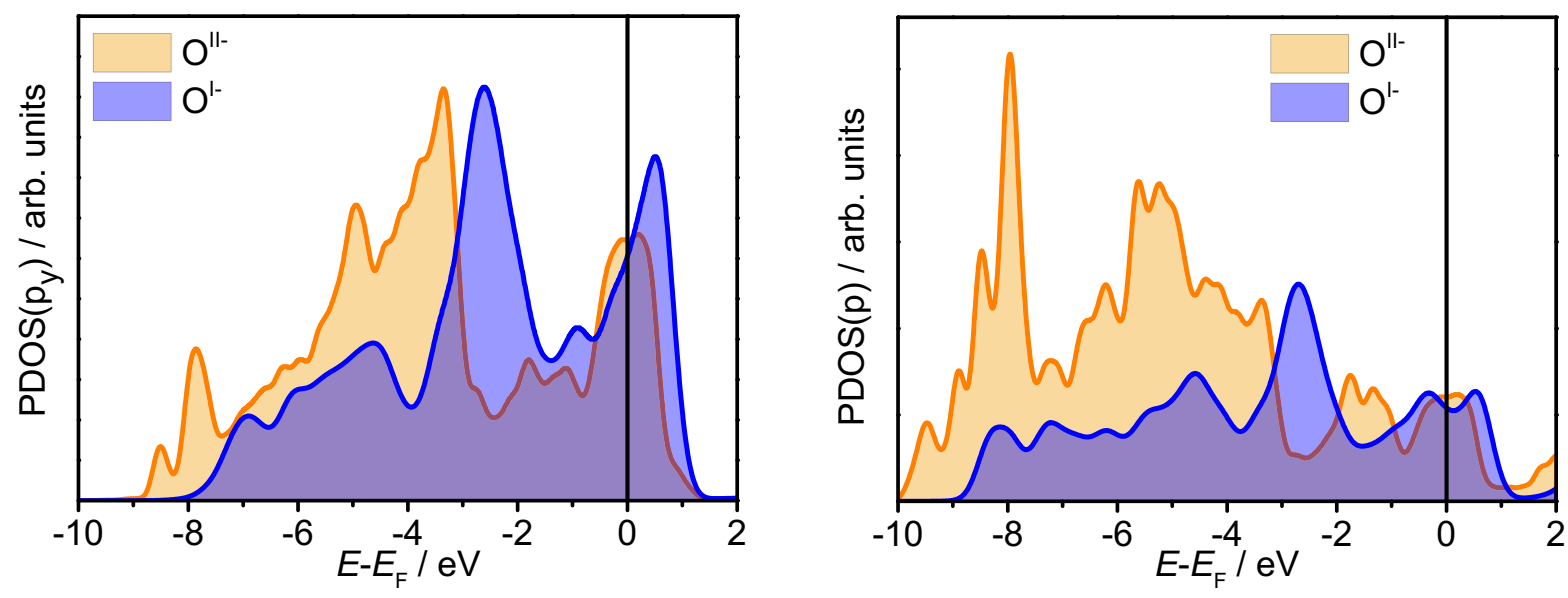

Figure S2.7.2: Projected density of states of (left) O 2py and (right) all O 2p orbitals for $\mathrm{O}^{\mathrm{I}-}$ and $\mathrm{O}^{\mathrm{II}-}$ species.

Figures S2.7.3 and S2.7.4 show comparisons of all Ir $5 \mathrm{~d}$ and O $2 \mathrm{p}$ states calculated for the entire rutile-type $\mathrm{IrO}_{2}$ cell without (see Figure 2.1) and with (see Figure 2.14) Ir vacancy. Introduction of the Ir vacancy leads to the creation of $\mathrm{O}^{\mathrm{I}-}$ and $\mathrm{Ir}^{\mathrm{III}}$. While the increased splitting of the $\mathrm{O} 2 \mathrm{p}$ orbitals near $E_{\mathrm{F}}$ may still be seen, it is significantly washed out when compared to the presentation in Figure S2.7.2 for only single $\mathrm{O}^{\mathrm{I}-}$ and $\mathrm{O}^{\mathrm{II}-}$ species. 

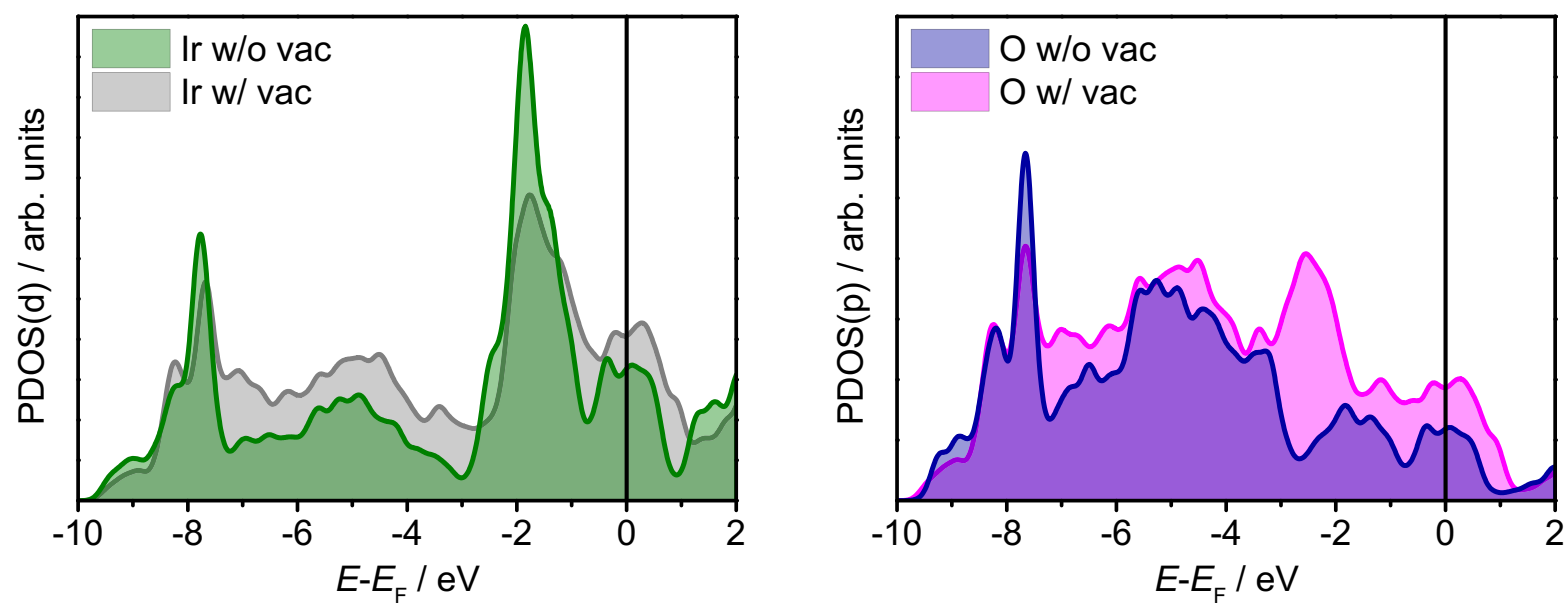

Figure S2.7.3: Projected density of states of all (left) Ir $5 d$ and (right) O 2p orbitals for rutile-type $\mathrm{IrO}_{2}$ without and with $\mathrm{Ir}$ vacancy, calculated using cells shown in Figures 2.1 and 2.14 .
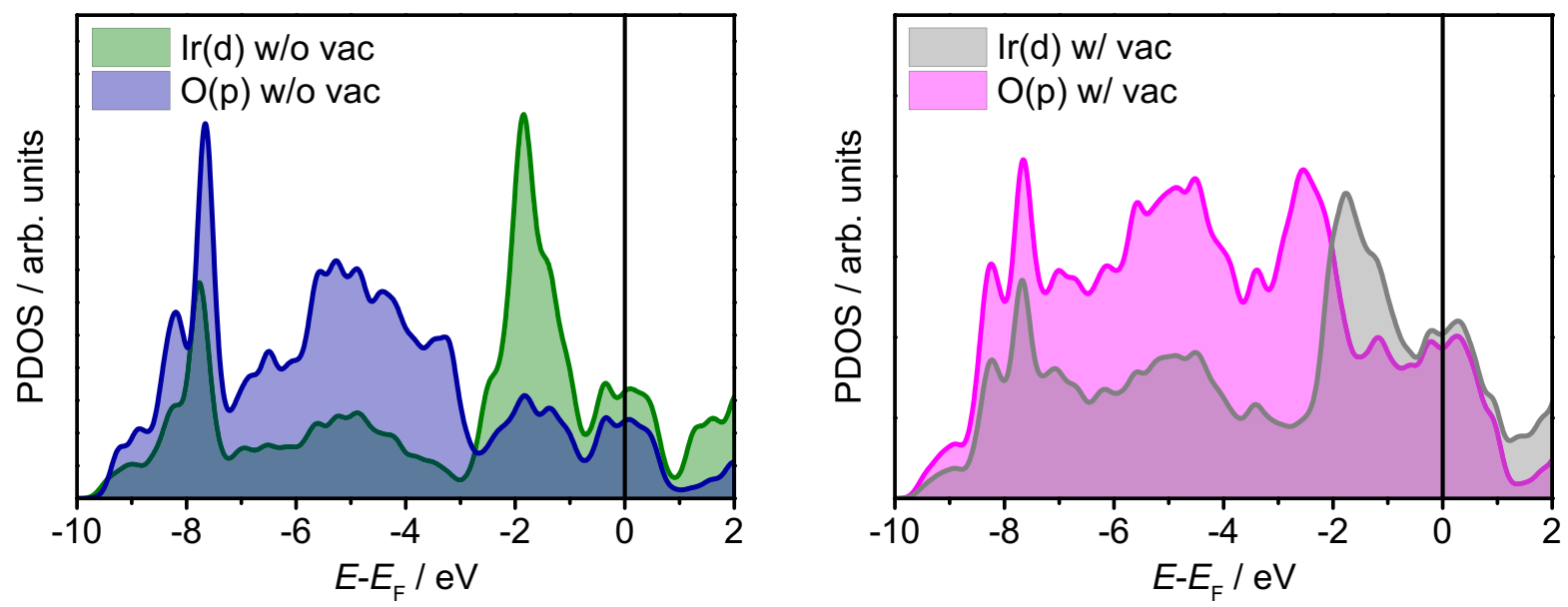

Figure S2.7.4: Projected density of states of all $\mathrm{Ir} 5 \mathrm{~d}$ and $\mathrm{O} 2 \mathrm{p}$ orbitals for rutiletype $\mathrm{IrO}_{2}$ without (left) and with (right) Ir vacancy, calculated using cells shown in Figures 2.1 and 2.14 .

Figure S2.7.5 shows a comparison of the measured valence bands and oxygen Kedges of rutile-type $\mathrm{IrO}_{2}$ and amorphous $\mathrm{IrO}_{\mathrm{x}}$. It may be seen that the valence band of amorphous $\mathrm{IrO}_{\mathrm{x}}$ has reduced intensity at $2 \mathrm{eV}$ and $0.5 \mathrm{eV}$ binding energy when compared to the prominent features in the rutile-type $\mathrm{IrO}_{2}$ at these energies. The intensity loss near $E_{\mathrm{F}}$ may allude to the deoccupation of $\mathrm{O} 2 \mathrm{p}$ states and the formation of additional $\mathrm{O} 2 \mathrm{p}$ hole states as suggested by the PDOS of $\mathrm{O}^{\mathrm{I}-}$ (see Figure S2.7.2). Nevertheless, since the valence band consists of contributions of both the Ir $5 \mathrm{~d}$ and the $\mathrm{O} 2 \mathrm{p}$ states, it is rather difficult to explicitly disentangle the respective contributions. However, when we consider the element-specific NEXAFS OK-edge of amorphous $\mathrm{IrO}_{\mathrm{x}}$, we are indeed able to confirm the deoccupation of $\mathrm{O} 2 \mathrm{p}$ states and the presence 
of additional $\mathrm{O} 2 \mathrm{p}$ hole states in amorphous $\mathrm{IrO}_{\mathrm{x}}$ by an additional resonance at $529 \mathrm{eV}$ that is absent in rutile-type $\mathrm{IrO}_{2}$. Therefore, monitoring the element-specific OK-edge presents a more direct and unequivocal way of observing the deoccupation of electronic states near $E_{\mathrm{F}}$ than the unspecific valence band measurements. Techniques to investigate changes in the occupied states near $E_{\mathrm{F}}$ in future investigations may be element-specific X-ray emission spectroscopies.
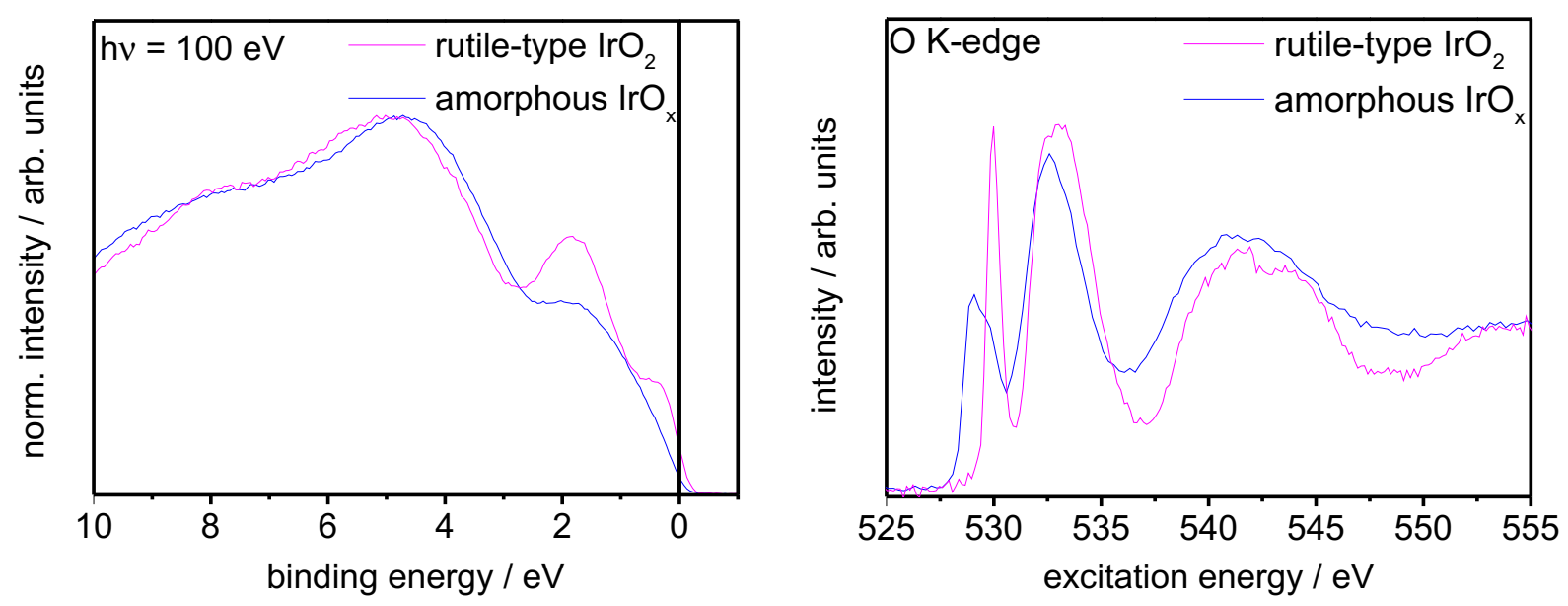

Figure S2.7.5: (left) Comparison of the measured valence band spectra of rutile-type $\mathrm{IrO}_{2}$ and amorphous $\mathrm{IrO}_{\mathrm{x}}$ normalized by maximum intensity. (right) Comparison of the OK-edges of rutile-type $\mathrm{IrO}_{2}$ and amorphous $\mathrm{IrO}_{x}$.

\section{Literature survey of Ir $4 \mathrm{f}$ line shape interpretations}

The Ir $4 \mathrm{f}$ line shape of iridium oxides and species contained in different types of iridium oxide have been heavily discussed in literature. The intrinsic asymmetric shape of stoichiometric rutile-type $\mathrm{IrO}_{2}$ was interpreted by Wertheim et al. ${ }^{16}$ as well as Kahk et al. ${ }^{17}$ Wertheim et al. do a full many body calculation of the line shape expected for rutile-type $\mathrm{IrO}_{2}$ while Kahk et al. reason their proposed screened and unscreened states by the Kotani model. ${ }^{47}$ Although Wertheim et al. predicted that in such an approach the unscreened state would have a binding energy $\approx 3 \mathrm{eV}$ above the main line, Kahk et al.'s fits use significantly lower values $(\approx 0.6 \mathrm{eV})$.

Table S2.7.1 gives a general overview of previously published XPS studies on iridium oxides (including both crystalline and amorphous forms) and one reference for $\mathrm{IrCl}_{3}$ with the proposed line shapes, contained species, and binding energy positions. In general, for rutile-type $\mathrm{IrO}_{2}$ powders most literature findings agree on an $\operatorname{Ir} 4 \mathrm{f}_{7 / 2}$ binding energy value of $61.7 \mathrm{eV}-61.9 \mathrm{eV}$ for $\mathrm{Ir}^{\mathrm{IV}}$. Only Hara et al. ${ }^{46}$ claim to have a considerable amount of $\mathrm{Ir}^{\mathrm{III}}$ in commercially available $\mathrm{IrO}_{2}$ powder and suggest a binding energy of $62 \mathrm{eV}$ for $\mathrm{Ir}^{\mathrm{III}}$ and 63.7 for $\mathrm{Ir}^{\mathrm{IV}}$. Similarly, Augustynski et al..$^{52}$ attribute a bind- 
ing energy of $61.6 \mathrm{eV}$ to $\mathrm{Ir}^{\mathrm{III}}$ in a compound of $\mathrm{Ir}_{2} \mathrm{O}_{3}$, for which no crystallographic data is available, though, and a binding energy of $62.7 \mathrm{eV}$ to $\mathrm{Ir}^{\mathrm{IV}}$ in $\mathrm{IrO}_{2}$.

Several groups deconvoluted the recorded Ir $4 \mathrm{f}$ spectra and proposed a wealth of different line shapes and interpretations of present Ir species. ${ }^{8,12,14,17,46,48,52}$ Especially the spectra of anodized iridium and of iridium oxyhydroxides were found to be broader and therefore suspected to contain more species than those of rutile-type $\mathrm{IrO}_{2}$.

By way of example, Augustynski et al. ${ }^{52}$ fitted an additional peak at $1.6 \mathrm{eV}$ above the main line of rutile-type $\mathrm{IrO}_{2}$ and attributed this to $\mathrm{Ir}^{\mathrm{VI}}$, which they suggested to be present in commercially available $\mathrm{IrO}_{2}$ due to surface oxidation. Similarly, Atanasoska et al. ${ }^{48}$ fitted peaks at $1.4 \mathrm{eV}$ and $6.3 \mathrm{eV}$ above the main line of rutile-type $\mathrm{IrO}_{2}$. These additional features have similar binding energies as those of the fit proposed in this work. However, in Atanasoska et al.'s ${ }^{48}$ fits, symmetric line shapes were used for the main line, which is unexpected for metallic conductors. In addition, they ascribed the peak seen at $1.4 \mathrm{eV}$ above the main line to Ir in an oxidation state of higher than IV, whereas we show in this work that the feature $\approx 1 \mathrm{eV}$ above the main line is a shake-up satellite of $\mathrm{Ir}^{\mathrm{IV}}$ species. Furthermore, Casalongue et al. ${ }^{14}$ assign an oxidation state of $\mathrm{V}$ to species appearing during OER at $0.7 \mathrm{eV}$ above their asymmetric main line. This assignment encouraged Nong et al. ${ }^{8}$ to also mention that the species they observe at higher binding energy after OER might be Ir with an oxidation state higher than IV. Finally, Kim et al. ${ }^{53}$ also discussed about the presence of $\operatorname{Ir}^{\mathrm{VI}}$ on anodized Ir electrodes since they observed intensity at binding energies $2.5 \mathrm{eV}$ above the main line. This small literature overview already witnesses the large discrepancies between the interpretation of different Ir $4 \mathrm{f}$ spectra.

It needs to be noted that all assignments of iridium oxidation states higher than IV were simply based on shifts of these components to higher binding energies, although Kötz et al. ${ }^{6}$ and Hall et al. ${ }^{12}$ had pointed out that there might be no correlation between a higher oxidation state and a higher binding energy of iridium species. In line with this advice, the Ir $4 \mathrm{f}$ binding energy of $\mathrm{IrCl}_{3}$, with Ir in oxidation state III, was found to be at higher values than those of rutile-type $\mathrm{IrO}_{2}$ with $\mathrm{Ir}$ in oxidation state IV $(62.6 \mathrm{eV}$ vs. $61.8 \mathrm{eV}$ ). Due to the lack of a well-defined reference material with Ir in oxidation state $\mathrm{V}$, such a material could not be characterized via XPS.

In the present study of the OER-active X-ray amorphous $\mathrm{IrO}_{x}$, neither from our TPR measurements nor from the charge balance in the employed defect model we see evidence for the presence of $\operatorname{Ir}^{\mathrm{V}}$ but only for $\mathrm{Ir}^{\mathrm{III}}$, which is why we attribute the additional peak located $0.6 \mathrm{eV}$ above the main line of $\operatorname{Ir}^{\mathrm{IV}}$ to $\mathrm{Ir}^{\mathrm{III}}$ species. 
Table S2.7.1: Literature values of $\operatorname{Ir} 4 \mathrm{f}_{7 / 2}$ binding energies of $\operatorname{IrO}_{x}$ and $\operatorname{IrCl}_{3}$. Fit shape abbreviations: GL:Gaussian-Lorentzian, G-DS: Gaussian convoluted Doniach-Šunjić, BE: binding energy

\begin{tabular}{|c|c|c|c|c|c|c|c|}
\hline & sample type & $\begin{array}{l}\mathrm{BE} / \\
\mathrm{eV}\end{array}$ & $\begin{array}{l}\text { type/ } \\
\text { fit shape }\end{array}$ & $\begin{array}{l}\mathrm{BE} / \\
\mathrm{eV}\end{array}$ & $\begin{array}{l}\text { type/ } \\
\text { fit shape }\end{array}$ & $\begin{array}{l}\mathrm{BE} / \\
\mathrm{eV}\end{array}$ & $\begin{array}{l}\text { type/ } \\
\text { fit shape }\end{array}$ \\
\hline $\begin{array}{l}\text { Atanasoska } \\
\text { et al. }{ }^{48}\end{array}$ & $\begin{array}{l}\mathrm{IrO}_{2} \text { (thermal } \\
\text { decomposition } \\
\left.\mathrm{IrCl}_{3}\right)\end{array}$ & 61.2 & $\mathrm{Ir}^{\mathrm{IV}} / \mathrm{GL}$ & 62.6 & $\mathrm{Ir}>\mathrm{IV} / \mathrm{GL}$ & 67.5 & $\begin{array}{l}\text { unknown/ } \\
\text { GL }\end{array}$ \\
\hline \multirow{3}{*}{$\begin{array}{l}\text { Augustynski } \\
\text { et al. } 52\end{array}$} & $\mathrm{IrO}_{2}$ & 62.7 & $\mathrm{Ir}^{\mathrm{IV}} / \mathrm{GL}$ & 64.3 & $\mathrm{Ir}^{\mathrm{VI}} / \mathrm{GL}$ & & \\
\hline & $\mathrm{Ir}_{2} \mathrm{O}_{3}$ & 61.6 & $\mathrm{Ir}^{\mathrm{III}} / \mathrm{GL}$ & & & & \\
\hline & anodic $\mathrm{IrO}_{\mathrm{x}}$ & 62.9 & $\mathrm{Ir}^{\mathrm{IV}} / \mathrm{GL}$ & 64.3 & $\mathrm{Ir}^{\mathrm{VI}} / \mathrm{GL}$ & & \\
\hline $\begin{array}{l}\text { Casalongue } \\
\text { et al. } 14\end{array}$ & $\begin{array}{l}\mathrm{Ir}^{\mathrm{IV}} \text { oxide } \\
\text { nanoparticles }\end{array}$ & 61.5 & $\mathrm{Ir}^{\mathrm{IV}} / \mathrm{G}-\mathrm{DS}$ & 62.2 & $\begin{array}{l}\mathrm{Ir}^{\mathrm{V}} \text { (only } \\
\text { present during } \\
\text { OER)/G-DS }\end{array}$ & & \\
\hline $\begin{array}{l}\text { Hall } \\
\text { et al. }{ }^{12}\end{array}$ & anodic $\mathrm{IrO}_{\mathrm{x}}$ & 61.2 & $\mathrm{Ir}^{\mathrm{IV}} / \mathrm{GL}$ & 63.1 & $\begin{array}{l}\text { oxide- } \\
\text { hydroxide/GL }\end{array}$ & & \\
\hline $\begin{array}{l}\text { Hara } \\
\text { et al. }{ }^{46}\end{array}$ & $\mathrm{IrO}_{2}$ powder & 62 & $\begin{array}{l}\mathrm{Ir}^{\mathrm{III}} / \\
\text { not specified }\end{array}$ & 63.7 & $\begin{array}{l}\mathrm{Ir}^{\mathrm{IV}} / \\
\text { not specified }\end{array}$ & & \\
\hline $\begin{array}{l}\text { Kahk } \\
\text { et al. }{ }^{17}\end{array}$ & $\mathrm{IrO}_{2}$ powder & 61.7 & $\begin{array}{l}\mathrm{Ir}^{\mathrm{IV}} \\
\text { screened/GL }\end{array}$ & 62.4 & $\begin{array}{l}\mathrm{Ir}^{\mathrm{IV}} \\
\text { unscreened/GL }\end{array}$ & 74.5 & $\begin{array}{l}\text { satellite/ } \\
\text { GL }\end{array}$ \\
\hline $\begin{array}{l}\text { Kim } \\
\text { et al. }{ }^{53}\end{array}$ & $\begin{array}{l}\mathrm{IrO}_{2} \text { powder / } \\
\text { anodized } \mathrm{Ir} \\
\text { electrode }\end{array}$ & 61.9 & $\mathrm{Ir}^{\mathrm{IV}} /$ no fit & 63.4 & $\mathrm{Ir}^{\mathrm{VI}} /$ no fit & & \\
\hline \multirow[t]{2}{*}{$\begin{array}{l}\text { Kötz } \\
\text { et al. }\end{array}$} & $\begin{array}{l}\mathrm{IrO}_{2} \text { (reactively } \\
\text { sputtered) }\end{array}$ & 61.8 & $\mathrm{Ir}^{\mathrm{IV}}$ no fit & & & & \\
\hline & anodic $\mathrm{IrO}_{\mathrm{x}}$ & 62.4 & $\begin{array}{l}\text { not specified/ } \\
\text { no fit }\end{array}$ & & & & \\
\hline \multirow[t]{2}{*}{$\begin{array}{l}\text { Peuckert } \\
\text { et al. }{ }^{13}\end{array}$} & $\begin{array}{l}\mathrm{IrO}_{2} \text { (thermally } \\
\text { oxidized } \mathrm{Ir} \text { ) }\end{array}$ & 61.9 & $\mathrm{Ir}^{\mathrm{IV}} /$ no fit & & & & \\
\hline & anodic $\mathrm{IrO}_{\mathrm{x}}$ & 61.2 & $\begin{array}{l}\text { not specified/ } \\
\text { no fit }\end{array}$ & & & & \\
\hline $\begin{array}{l}\text { Wertheim } \\
\text { et al. }{ }^{16}\end{array}$ & $\begin{array}{l}\mathrm{IrO}_{2} \text { single } \\
\text { crystal }\end{array}$ & 61.6 & $\begin{array}{l}\mathrm{Ir}^{\mathrm{IV}} / \text { calcu- }^{-} \\
\text {lated asym. }\end{array}$ & & & & \\
\hline Folkesson ${ }^{54}$ & $\mathrm{IrCl}_{3}$ & 62.6 & $\operatorname{Ir}^{\mathrm{III}}$ & & & & \\
\hline
\end{tabular}


An alternative technique to monitor the oxidation state of Ir is X-ray absorption spectroscopy, which several groups have used in situ to relate changes in the white line of the Ir L-edge with the present Ir oxidation state. ${ }^{55-57}$ For electrodeposited, hydrated Ir oxyhydroxide films, it was observed that the white line is broadened and shifted to higher excitation energies with increased potential. In comparison with reference compounds $\left(\mathrm{IrO}_{2}\right.$ and $\left.\mathrm{IrCl}_{3}\right)$, these results were interpreted as to initially have Ir in oxidation states III and IV and to later have in addition Ir in an oxidation state of up to $\mathrm{V}$ present during OER. All these studies restricted their investigations to monitoring changes in the metal states, whereas possible changes in their environment, hence the oxygen states, were not considered.

\section{Acknowledgments}

The authors acknowledge BESSY II/HZB for granting beam time at the ISISS beam line under the proposal \#14201159 and support during measurements. 


\section{References}

[1] J. P. Barton, D. G. Infield, IEEE T. Energy Conver. 2004, 19, 441.

[2] C. C. L. McCrory, S. Jung, J. C. Peters, T. F. Jaramillo, J. Am. Chem. Soc. 2013, 135, 16977.

[3] M. Carmo, D. L. Fritz, J. Mergel, D. Stolten, Int. J. Hydrogen Energy 2013, 38, 4901.

[4] A. Damjanovic, A. Dey, J. O. M. Bockris, J. Electrochem. Soc. 1966, 113, 739.

[5] S. Trasatti, J. Electroanal. Chem. Interfacial Electrochem. 1980, 111, 125.

[6] R. Kötz, H. Neff, S. Stucki, J. Electrochem. Soc. 1984, 131, 72.

[7] D. N. Buckley, L. D. Burke, J. Chem. Soc., Faraday Trans. 1 1975, 71, 1447.

[8] H. N. Nong, H.-S. Oh, T. Reier, E. Willinger, M.-G. Willinger, V. Petkov, D. Teschner, P. Strasser, Angew. Chem. Int. Ed. 2015, 54, 2975.

[9] M. Bernicke, E. Ortel, T. Reier, A. Bergmann, J. Ferreira de Araújo, P. Strasser, R. Kraehnert, ChemSusChem 2015, 8, 1908.

[10] T. Reier, D. Teschner, T. Lunkenbein, A. Bergmann, S. Selve, R. Kraehnert, R. Schlögl, P. Strasser, J. Electrochem. Soc. 2014, 161, F876.

[11] R. Kötz, H. J. Lewerenz, P. Brüesch, S. Stucki, J. Electroanal. Chem. Interfacial Electrochem. 1983, 150, 209.

[12] Y. H. Hall, P. M. A. Sherwood, J. Chem. Soc., Faraday Trans. 1 1984, 80, 135.

[13] M. Peuckert, Surf. Sci. 1984, 144, 451.

[14] H. G. Sanchez Casalongue, M. L. Ng, S. Kaya, D. Friebel, H. Ogasawara, A. Nilsson, Angew. Chem. Int. Ed. 2014, 53, 7169.

[15] S. K. Panda, S. Bhowal, A. Delin, O. Eriksson, I. Dasgupta, Phys. Rev. B 2014, 89, 155102.

[16] G. K. Wertheim, H. J. Guggenheim, Phys. Rev. B 1980, 22, 4680.

[17] J. M. Kahk, C. G. Poll, F. E. Oropeza, J. M. Ablett, D. Céolin, J.-P. Rueff, S. Agrestini, Y. Utsumi, K. D. Tsuei, Y. F. Liao, F. Borgatti, G. Panaccione, A. Regoutz, R. G. Egdell, B. J. Morgan, D. O. Scanlon, D. J. Payne, Phys. Rev. Lett. 2014, 112, 117601. 
[18] L. Atanasoska, P. Gupta, C. Deng, R. Warner, S. Larson, J. Thompson, ECS Trans. 2009, 16, 37.

[19] S. Kühl, A. Tarasov, S. Zander, I. Kasatkin, M. Behrens, Chem. - Eur. J. 2014, 20, 3782.

[20] A. Knop-Gericke, E. Kleimenov, M. Hävecker, R. Blume, D. Teschner, S. Zafeiratos, R. Schlögl, V. I. Bukhtiyarov, V. V. Kaichev, I. P. Prosvirin, A. I. Nizovskii, H. Bluhm, A. Barinov, P. Dudin, M. Kiskinova, X-Ray Photoelectron Spectroscopy for Investigation of Heterogeneous Catalytic Processes, in B. C. Gates, H. Knözinger, Eds., Advances in Catalysis, Vol. 52, Academic Press, 2009, pp. 213 272.

[21] S. Tanuma, C. J. Powell, D. R. Penn, Surf. Interface Anal. 1994, 21, 165.

[22] M. Hävecker, M. Cavalleri, R. Herbert, R. Follath, A. Knop-Gericke, C. Hess, K. Hermann, R. Schlögl, Phys. Status Solidi B 2009, 246, 1459.

[23] N. Fairley, A. Carrick, The Casa Cookbook: Recipes for XPS data processing, Acolyte Science, Knutsford, 2005.

[24] G. D. Mahan, Many-Particle Physics, Springer Science \& Business Media, New York, USA, 2013.

[25] S. Doniach, M. Šunjić, J. Phys. C: Solid State Phys. 1970, 3, 285.

[26] A. Rosencwaig, G. K. Wertheim, H. J. Guggenheim, Phys. Rev. Lett. 1971, 27, 479.

[27] J. P. Perdew, K. Burke, M. Ernzerhof, Phys. Rev. Lett. 1996, 77, 3865.

[28] P. Giannozzi, S. Baroni, N. Bonini, M. Calandra, R. Car, C. Cavazzoni, D. Ceresoli, G. L. Chiarotti, M. Cococcioni, I. Dabo, A. Dal Corso, S. de Gironcoli, S. Fabris, G. Fratesi, R. Gebauer, U. Gerstmann, C. Gougoussis, A. Kokalj, M. Lazzeri, L. Martin-Samos, N. Marzari, F. Mauri, R. Mazzarello, S. Paolini, A. Pasquarello, L. Paulatto, C. Sbraccia, S. Scandolo, G. Sclauzero, A. P. Seitsonen, A. Smogunov, P. Umari, R. M. Wentzcovitch, J. Phys.: Condens. Matter 2009, 21, 395502.

[29] A. Dal Corso, Comp. Mater. Sci. 2014, 95, 337 .

[30] N. Marzari, D. Vanderbilt, A. De Vita, M. C. Payne, Phys. Rev. Lett. 1999, 82, 3296.

[31] A. A. Bolzan, C. Fong, B. J. Kennedy, C. J. Howard, Acta Crystallogr. B 1997, 53, 373. 
[32] T. E. Jones, T. C. R. Rocha, A. Knop-Gericke, C. Stampfl, R. Schlögl, S. Piccinin, Phys. Chem. Chem. Phys. 2015, 17, 9288.

[33] E. Pehlke, M. Scheffler, Phys. Rev. Lett. 1993, 71, 2338.

[34] C. Gougoussis, M. Calandra, A. P. Seitsonen, F. Mauri, Phys. Rev. B 2009, 80, 075102 .

[35] M. Taillefumier, D. Cabaret, A.-M. Flank, F. Mauri, Phys. Rev. B 2002, 66, 195107.

[36] A. Menzel, S. Benzaid, M. O. Krause, C. D. Caldwell, U. Hergenhahn, M. Bissen, Phys. Rev. A 1996, 54, R991.

[37] P. J. W. Weijs, M. T. Czyżyk, J. F. van Acker, W. Speier, J. B. Goedkoop, H. van Leuken, H. J. M. Hendrix, R. A. de Groot, G. van der Laan, K. H. J. Buschow, G. Wiech, J. C. Fuggle, Phys. Rev. B 1990, 41, 11899.

[38] V. Mauchamp, M. Jaouen, P. Schattschneider, Phys. Rev. B 2009, 79, 235106.

[39] A. Minguzzi, O. Lugaresi, E. Achilli, C. Locatelli, A. Vertova, P. Ghigna, S. Rondinini, Chem. Sci. 2014, 5, 3591.

[40] A. Minguzzi, C. Locatelli, O. Lugaresi, E. Achilli, G. Cappelletti, M. Scavini, M. Coduri, P. Masala, B. Sacchi, A. Vertova, P. Ghigna, S. Rondinini, ACS Catal. 2015, 5, 5104 .

[41] P. A. Zhdan, G. K. Boreskov, A. I. Boronin, W. F. Egelhoff, W. H. Weinberg, Surf. Sci. 1976, 61, 25.

[42] J. F. van der Veen, F. J. Himpsel, D. E. Eastman, Phys. Rev. Lett. 1980, 44, 189.

[43] S. Hüfner, G. Wertheim, J. Wernick, Solid State Commun. 1975, 17, 417.

[44] P. Lacovig, M. Pozzo, D. Alfè, P. Vilmercati, A. Baraldi, S. Lizzit, Phys. Rev. Lett. 2009, 103, 166101.

[45] J. Yeh, I. Lindau, At. Data Nucl. Data Tables 1985, 32, 1.

[46] M. Hara, K. Asami, K. Hashimoto, T. Masumoto, Electrochim. Acta 1983, 28, 1073.

[47] A. Kotani, J. Electron Spectrosc. Relat. Phenom. 1996, 78, 7.

[48] L. Atanasoska, R. Atanasoski, S. Trasatti, Vacuum 1990, 40, 91 .

[49] S. W. Gaarenstroom, N. Winograd, J. Chem. Phys. 1977, 67, 3500. 
[50] N. Nücker, M. Merz, P. Schweiss, E. Pellegrin, S. Schuppler, T. Wolf, V. Chakarian, J. Freeland, Y. U. Idzerda, M. Kläser, G. Müller-Vogt, G. Er, S. Kikkawa, G. Liu, J. Supercond. 1999, 12, 143.

[51] C. T. Chen, F. Sette, Y. Ma, M. S. Hybertsen, E. B. Stechel, W. M. C. Foulkes, M. Schulter, S.-W. Cheong, A. S. Cooper, L. W. Rupp, B. Batlogg, Y. L. Soo, Z. H. Ming, A. Krol, Y. H. Kao, Phys. Rev. Lett. 1991, 66, 104.

[52] J. Augustynski, M. Koudelka, J. Sanchez, B. E. Conway, J. Electroanal. Chem. 1984, 160, 233.

[53] K. S. Kim, C. D. Sell, N. Winograd, ESCA studies of metal and metal electrode surfaces, in M. W. Breiter, Editor, Proceedings of the Symposium on Electrocatalysis, Physical Electrochemistry Devision, Electrochemical Society, Princeton, New Jersey, 1974, pp. 242-257.

[54] B. Folkesson, Acta Chem. Scand. 1973, 27, 287.

[55] W.-H. Chung, C.-C. Wang, D.-S. Tsai, J.-C. Jiang, Y.-C. Cheng, L.-J. Fan, Y.-W. Yang, Y.-S. Huang, Surf. Sci. 2010, 604, 118.

[56] Y. B. Mo, I. C. Stefan, W. B. Cai, J. Dong, P. Carey, D. A. Scherson, J. Phys. Chem. B 2002, 106, 3681.

[57] A. R. Hillman, M. A. Skopek, S. J. Gurman, Phys. Chem. Chem. Phys. 2011, 13, 5252. 